\title{
The Effect of Heating Rates on Low Temperature Hexane Air Combustion
}

\author{
P. A. Boettcher ${ }^{\mathrm{a}, *}$, R. Mével ${ }^{\mathrm{a}}$, V. Thomas ${ }^{\mathrm{a}}$, J. E. Shepherd ${ }^{\mathrm{a}}$ \\ ${ }^{a}$ Graduate Aerospace Laboratories, California Institute of Technology, Pasadena, \\ California 91125, USA
}

\begin{abstract}
Combustion of hydrocarbon fuels is traditionally separated into slow reaction, cool flame, and ignition regimes based on pressure and temperature. Standard tests, such as the ASTM E659, are used to determine the lowest temperature required to ignite a specific fuel mixed with air at atmospheric pressure. It is expected that the initial pressure and the rate at which the mixture is heated also influences the limiting temperature and the type of combustion. This study investigates the effect of heating rate, between 4 and $15 \mathrm{~K} / \mathrm{min}$, and initial pressure, in the range of 25 to $100 \mathrm{kPa}$, on ignition of $n$-hexane air mixtures. Mixtures with equivalence ratio ranging from $\Phi=0.6$ to $\Phi=1.2$ were investigated. The problem is also modeled computationally using an extension of Semenov's classical autoignition theory with a detailed chemical mechanism. Experiments and simulations both show that in the same reactor either a slow reaction or an ignition event can take place depending on the heating rate. Analysis of the detailed chemistry demonstrates that a mixture which approaches the ignition region slowly undergoes a significant modification of its composition. This change in composition induces a progressive shift of the explosion limit until the mixture is no longer flammable. A mixture that approaches the ignition region sufficiently rapidly undergoes only a moderate amount of thermal decomposition and explodes quite violently.
\end{abstract}

Keywords: $n$-hexane oxidation, direct absorption, heating rate

\footnotetext{
${ }^{*}$ Corresponding Author

Email address: philipp@caltech.edu (P. A. Boettcher)
} 


\section{Introduction}

Ignition of fuel in the fuel tank or surrounding flammable leakage zones is one of the main safety concerns for the commercial aviation industry. The presence of hot surfaces is unavoidable in aircraft. Consequently, ignition by hot surfaces close to the autoignition temperature is particularly relevant to design of fuel handling systems and analysis of hazards in aviation and industrial settings. While the ASTM E659 is a standard test for autoignition temperature, only the minimum temperature for ignition at atmospheric pressure is determined $[1,2]$ for a particular geometry and size. The specific mixture composition is neither controlled nor measured since the liquid test fuel is injected into a heated open vessel. The contents are not actively mixed and it is presumed that a considerable range of composition exists within pockets of gas in the vessel as evaporation of liquid fuel occurs [3]. It can also be expected that numerous parameters, including the pressure, the composition, the size and shape of the vessel, and the rate at which the mixture is heated, will influence the limiting temperature and the type of combustion event. In prior laboratory research, the combustion products have either been condensed and the liquid analyzed later [4], or a gas chromatograph was used to analyze a small sample at a maximum frequency of about $0.1 \mathrm{~Hz}$ [5]. Additional work was done in rapid compression machines at higher temperatures (600 K - $800 \mathrm{~K})$ [6] and gas sampling techniques [7, 8]. While pressure transients are easily captured in these experiments, fast and accurate fuel concentration measurements requiring optical techniques have never previously been applied to the autoignition phenomenon.

The objective of this study is to investigate the effects of heating rate, composition, and initial pressure on the thermal ignition processes that can occur when hydrocarbon fuels come in contact with heated elements by using an experimental setup that allows for precise control of the gas composition and temperature, and a fast measurement rate of the fuel content. Hexane was selected as a test fuel. It has a similar autoignition temperature (498 $\mathrm{K}[9,10])$ to kerosene and is comparable to jet fuel (511 K turbine fuel [11], Jet A [2]). Hexane is easy to handle in liquid form but vaporizes readily, and detailed chemical reaction mechanisms are available. In the following section, the experimental setup and the modeling approach are described. Then, the experimental results are presented. Finally, the results are interpreted based on an extension of Semenov's classical autoignition theory with a detailed chemical mechanism. 


\section{Experimental Setup and Modeling Approach}

\subsection{Experimental Setup}

The test vessel (Figure 1) is a closed $400 \mathrm{~mL}$ Pyrex cell (surface to volume ratio $\left.\approx 0.85 \mathrm{~cm}^{-1}\right)$. Prior to experiments, the test cell is evacuated to less than $10 \mathrm{~Pa}$. The vessel is filled with $n$-hexane, nitrogen, and oxygen using the partial pressure method, then thoroughly mixed by a circulation pump. Hexane is injected as a liquid through a septum at a partial pressure below its vapor pressure in order to ensure complete vaporization. The uncertainty in composition is $\pm 0.01 \mathrm{kPa}$ for each species, due to the accuracy of the pressure measurement. Two sapphire windows are spaced $9 \mathrm{~cm}$ apart, providing optical access for the laser measurement. The vessel is suspended inside an aluminum shell with an air gap of approximately $3 \mathrm{~mm}$, and the shell is heated by two band heaters rated at a total of $800 \mathrm{~W}$. The temperature inside the vessel is measured by a K-type thermocouple that has been coated with silica in order to avoid catalytic effects. During the experiment, transient pressure is measured with a separate fast-response static pressure gage $(\geq 10 \mathrm{kHz})$. The final heating rate is computed from the pressure measurements using the values before the onset of the reaction, i.e. assuming no change in moles, using

$$
\frac{d T}{d t}=\frac{V}{n \tilde{R}} \frac{d P}{d t}
$$

because the response time of the pressure transducer is much shorter than that of the thermocouple. The data is directly analyzed and averaged giving an effective sampling rate of $8 \mathrm{~Hz}$. Experiments were performed at three total pressures: 26,67 , and $101 \mathrm{kPa}$, three equivalence ratios, $\Phi: 0.6,1$, and 1.2 , and heating rates between $4 \mathrm{~K} / \mathrm{min}$ and $14 \mathrm{~K} / \mathrm{min}$.

The fuel concentration is measured by direct absorption $[12,13]$. A commercially available $3.39 \mu \mathrm{m}$ HeNe laser is passed through a chopper running at $300 \mathrm{~Hz}$. The beam is split two ways before entering the test cell through a $0.5 \mathrm{~mm}$ thin sapphire window. The main beam is passed through the test cell and measured by a detector on the other side, while the second beam is sent to a reference detector to correct for variations in the initial laser intensity. High angles of incidence $\left(\sim 10^{\circ}\right)$ were used to avoid intensity changes due to interference effects from the windows caused by thermal expansion since internal reflections are scattered through a wider angle.

The $n$-hexane mole fraction is calculated from the detected laser transmission using Beer's law. The $\mathrm{C}-\mathrm{H}$ bond in any hydrocarbon molecule ab- 
sorbs around the $3.39 \mu \mathrm{m}$ wavelength, so changes from $n$-hexane into other hydrocarbon molecules cannot be detected. Thus an equivalent $n$-hexane mole fraction, $X_{C_{6} H_{14}}^{*}$, is calculated based on the absorption cross section of $n$-hexane, which is found through separate calibration experiments to be $\sigma_{\nu}=38 \pm 1 \mathrm{~m}^{2} /$ mole. This value is in agreement with values from the literature (Jaynes and Beam found $45 \mathrm{~m}^{2} /$ mole [14], Drallmeier $38.5 \pm 2$ $\mathrm{m}^{2} /$ mole [13, 12], Tsuboi et al. $36.2 \pm 7 \mathrm{~m}^{2} /$ mole [15, 12], Mevel et al. 39.92 $\pm 2 \mathrm{~m}^{2} /$ mole [34]). The intensity changes are converted to equivalent mole fractions using the intensity measurements:

$$
\begin{gathered}
\frac{I}{I_{0}}=\exp \left(-\frac{\sigma_{\nu} P_{\text {fuel }} L}{\tilde{R} T}\right) \\
X_{C_{6} H_{14}}^{*}=\frac{P_{\text {fuel }}}{P_{\text {total }}}=\frac{\tilde{R} T}{\sigma_{\nu} L P_{\text {total }}}\left[\ln \left(\frac{I_{1}(t)}{I_{2}(t)}\right)-\ln \left(\frac{I_{1}^{0}}{I_{2}^{0}}\right)\right]
\end{gathered}
$$

\subsection{Modeling Approach}

The experiment is modeled using Semenov's theory [16] for thermal ignition, assuming a well stirred constant volume reactor filled with a uniform mixture of $n$-hexane in air. The wall temperature is increased from room temperature at a constant rate, $\alpha$, which is included in the energy equation as: $T_{w}=T_{w}^{0}+\alpha t$. The temperature variation with time is computed from the energy conservation equation:

$$
V \rho c_{v} \frac{d T}{d t}=V \sum_{i=1}^{k} \dot{\omega}_{i} u_{i}+S h\left(T_{w}^{0}+\alpha t-T\right)=\dot{q}_{r}+\dot{q}_{w} .
$$

The species variation with time is computed with the mass conservation equation

$$
\frac{d Y_{i}}{d t}=\frac{W_{i} \dot{\omega}_{i}}{\rho}, i=1,2, \ldots, k
$$

where $k$ is the total number of species. The vessel volume, $V$, and surface area, $S$, are constant while the density, $\rho$, and specific heat at constant volume, $c_{v}$, are calculated at each solver time step. The heat transfer is modeled with Newton's law of cooling using a lumped parameter, $h$, to approximate free convection inside the vessel. The change in temperature is determined by the competition between the chemical heat release, $\dot{q}_{r}$, and the heat loss rate, 
$\dot{q}_{w}$, into which the terms of the energy equation have been grouped. Cantera [17] is used to compute the net chemical production rate, $\dot{\omega}_{i}$, utilizing a detailed chemistry mechanism, as well as all thermodynamic properties for both individual species, such as the internal energy $u_{i}$, and the gas mixture

as a whole. A variable-coefficient ODE solver (VODE) is used to integrate the system of equations [18].

The basis for our reaction mechanism is the detailed model of Ramirez et al. [19]. This kinetic scheme was developed to model decane and biofuel chemistry. Further validation for $n$-hexane was necessary for the present study; this is presented along with the modeling results. The mixture is initialized at a given pressure, temperature, and equivalence ratio, and then the energy equation is integrated forward in time with the wall temperature rising at a specified rate, $\alpha$.

\section{Experimental Results}

Experiments were performed varying the composition, initial pressure, and heating rate applied to the vessel walls. Figures 2 and 3 show the temperature, pressure, and fuel mole fraction during two representative experiments performed with a slightly fuel rich mixture $(\Phi=1.2,2.6 \% n$-hexane in air) and at an initial pressure of $101 \mathrm{kPa}$. The mixture of Fig. 2 was heated at a rate of $4.25 \mathrm{~K} / \mathrm{min}$ and underwent a slow reaction. A slow reaction case is characterized by a slow consumption of the fuel with a minimal pressure rise. The mixture of Fig. 3 was heated at $11 \mathrm{~K} / \mathrm{min}$ and underwent ignition. In this context, an event characterized by rapid consumption of the fuel accompanied by a large pressure rise will be referred to as either an ignition case or fast reaction case.

The slow reaction case (Fig. 2) has several features that make it significantly different from the ignition case. As the temperature increases from room temperature, we observe a slow consumption of the fuel ( $\mathrm{C}-\mathrm{H}$ bonds) starting at $500 \mathrm{~K}(2500 \mathrm{~s})$, which reduces the fuel concentration from $2.6 \%$ to $0.45 \%$ over $250 \mathrm{~s}$ until the heating system is turned off at $540 \mathrm{~K}$. During this time neither the pressure nor the temperature rises above the trajectory prescribed by the input heating rate.

The temperature and pressure plot show small steps in the ramp from room temperature to $540 \mathrm{~K}$. These steps are due to the response time of the controller and the aluminum shell to the overall heating rate and temperature change during the initial fuel consumption is $4.25 \mathrm{~K} / \mathrm{min}$. 
Heating the same mixture $(\Phi=1.2)$ at roughly twice the heating rate, $11 \mathrm{~K} / \mathrm{min}$, results in a fast reaction (Fig. 3). Upon ignition, we observe a spike in pressure, reaching a peak of $330 \mathrm{kPa}$ with elevated pressure for 0.5 seconds. The temperature peak is visible but substantially smaller due to the much slower response time of the thermocouple as compared to the pressure transducer.

From the changes in the fuel concentration, temperature, and pressure measurements, we observe that the fast reaction occurs at $1010 \mathrm{~s}$. At this time, we estimate the temperature in the vessel to be $473 \mathrm{~K}\left(200{ }^{\circ} \mathrm{C}\right)$, whereas the thermocouple reads $400 \mathrm{~K}$. Due to the limited response rate of the thermocouple, discussed earlier, the actual gas temperature must be inferred from the pressure measurements, assuming the mixture is an ideal gas and negligible changes in the number of moles. At $1000 \mathrm{~s}$ we see an initial decrease in fuel concentration followed by a rapid consumption of the fuel during the ignition transient at $\sim 1010 \mathrm{~s}$. Unlike the slow reaction, in this case the response of the measurement system is limited by signal contamination from light emission during the ignition.

The effect of initial pressure and composition was examined for 14 conditions and the outcomes are shown in Figure 4. The following changes in the experimental conditions transition the system from a slow reaction case to an ignition case: (1) increasing the pressure (between $26 \mathrm{kPa}-100 \mathrm{kPa}$ ), (2) increasing the heating rate $(4-12 \mathrm{~K} / \mathrm{min})$, (3) increasing the equivalence ratio in the region investigated $(\Phi=0.6-1.25)$. Each of these factors is confirmed experimentally, while keeping the other two parameters constant.

\section{Modeling}

In order to model this system, a detailed kinetic scheme had to be identified and validated against appropriate low temperature data. Although hydrocarbons have been widely studied, there exists little data concerning $n$-hexane oxidation [20]. Curran et al. [21] studied hexane isomer chemistry through the modeling and measurement of exhaust gases from an engine. Shock tube experiments have been performed by Burcat et al. [22] and Zhukov et al. [23]. Kelley et al. [24] recently reported laminar flame speeds for C-5 to C-8 n-alkanes. To our knowledge, no low temperature experimental data exists for $n$-hexane-oxygen mixtures. It should also be noted that no single detailed kinetic scheme is available to model $n$-hexane combustion chemistry from low to high temperature. In order to describe the kinetics 
of $n$-hexane-air mixtures, we employed the $\mathrm{C}-7$ basis of the detailed model published by Ramirez et al. [19] which includes $n$-hexane.

\subsection{Kinetic scheme validation}

For validation at high temperature, we used the experimental data of Burcat et al. and Zhukov et al. For validation at intermediate and low temperature, we used n-heptane flow reactor and jet stirred reactor data from Held et al. [25] and Dagaut et al. [26], respectively.

The experimental $n$-hexane-oxygen-diluent mixture auto-ignition delay times from Burcat et al. [22] and Zhukov et al. [23] are compared in Fig. 5 to the predictions of the Ramirez model. The computed delay times are in reasonable agreement with the experimental results. Although the model typically underestimates the results of Burcat in the high temperature range, the mean relative error does not exceed 30\%. The mean error with respect to the data of Zhukov is around 25\%. Considering the usual uncertainty of $20 \%$ associated with shock-tube delay times, the model reproduces the experimental data adequately for the purpose of the present study.

The flow reactor experimental data from Held et al. [25] are compared in Fig. 6 (a) to the model predictions for a lean n-heptane-oxygen-nitrogen mixture. The temporal mole fraction profiles of the main species are relatively well predicted. The consumption of both reactants, $\mathrm{C}_{7} \mathrm{H}_{16}$ and $\mathrm{O}_{2}$, are satisfactorily predicted throughout the experiment, whereas the production of $\mathrm{CH}_{4}$ and $\mathrm{C}_{2} \mathrm{H}_{4}$ are overestimated early in the oxidation process, and $\mathrm{CO}$

mole fraction is underestimated. It should also be noted that the temperature profiles (not shown) are in good agreement with experiments.

The jet-stirred reactor experimental data from Dagaut et al. and the model predictions are compared in Fig. 6 (b) for a stoichiometric n-heptaneoxygen-nitrogen mixture. The $\mathrm{CO}$ mole fraction is well predicted everywhere except within the the region with a negative temperature coefficient (NTC), where an increase in temperature leads to longer induction times (700 - 800 $\mathrm{K})$. The $\mathrm{CO}_{2}$ mole fraction is underestimated in the low temperature range, but is in close agreement in the high temperature range. The $\mathrm{CH}_{4}$ mole fraction is overestimated almost throughout the temperature range. Finally, it can be noted that the NTC region position is correctly predicted.

The last experimental datum to be modeled in testing the validity of the detailed kinetic scheme is the auto-ignition temperature. The experimental value is near $500 \mathrm{~K}$ for a stoichiometric $n$-hexane-air mixture at atmospheric 
pressure. The predicted temperature, based on a constant-volume reactor simulation, is $540 \mathrm{~K}$.

Although the model is not able to reproduce the whole set of selected experimental data with good accuracy, the general trends of $n$-hexane-oxygen mixture reactivity are predicted. A better agreement might be obtained by adjusting the dominant kinetic parameters. However, this would require additional experimental data and is beyond the scope of the present study.

\subsection{Fast and slow combustion modeling}

The purpose of the modeling study was to determine if an existing reaction mechanism could qualitatively reproduce the observed trends using a simple reactor model that simulates the key features of the present experimental set-up. The reactor was modeled as a homogenous mixture in a closed, fixed volume with a specified wall temperature that is a function of time. Heat transfer from the vessel wall to the contents is characterized thorough the wall heat transfer coefficient, $h$, with a value of $15 \mathrm{~W} /\left(\mathrm{m}^{2} \mathrm{~K}\right)$. The value of the heat transfer coefficient was determined iteratively until the switch between the slow and fast reaction was observed for heating rates of 5 and $10 \mathrm{~K} / \mathrm{min}$ and is consistent with heat transfer from free convection of gases [27].

Figures 7 and 8 present the simulation results for a slow reaction and an ignition event corresponding to a rich mixture, $\Phi=1.2$, with heating rates of 5 and $10 \mathrm{~K} / \mathrm{min}$, respectively. In the case of the slow reaction, a slight increase in temperature and pressure can be seen around $2900 \mathrm{~s}$. This time corresponds to the maximum rate of $n$-hexane and oxygen consumption. The reactant consumption extends over a long period of time, several hundred seconds. Although the mixture is rich, only $75 \%$ of the oxygen is consumed after $3100 \mathrm{~s}$. In the case of the ignition event, a sharp increase in temperature and pressure is observed at about $1500 \mathrm{~s}$. At this time, the reactants are consumed and products are formed over a short period of time, on the order of tens of milliseconds. Figures 7 and 8 demonstrate that reactant consumption proceeds at essentially constant temperature and pressure in the case of a slow reaction event, and tends towards a constant volume explosion in the case of a fast combustion event.

It is remarkable that a variation of a factor of two in the heating rate results in a completely different mode of combustion in these two cases. Further the temperature at which strong reactant consumption occurs is 
actually lower in the higher heating rate case $(473 \mathrm{~K})$ than in the lower heating case $(500 \mathrm{~K})$.

\subsection{Heat production and losses}

In order to help understand the differences between the slow reaction and ignition cases, the heat production and loss rates have been calculated, along with the energy release rate for each elementary reaction (Figures 9 and 10).

The heat release term, $\dot{q}_{r}$, and the magnitude of the heat loss term, $\left|\dot{q}_{w}\right|$, from Equation 4, are shown in Figure 9 (note that the time axes are scaled so that temperature history will coincide in the absence of chemical reactions). The initial value of the heat loss term corresponds directly to the heating rate to the reactor. The inset shows the slight lag of the heat loss term in comparison to the heat release term. For the slow reaction case the difference diminishes as the reaction becomes less exothermic, while for the ignition case the difference increases as mixture move towards the ignition point. In the slow reaction case, the chemical heat release is balanced by heat loss at the wall. In the ignition case, the energy release exceeds the heat loss at the wall by several orders of magnitude when ignition occurs. The energy release by the chemical reactions is $\sim 10^{7}$ times greater during an ignition case than during the slow reaction case. The difference in chemical reaction pathways is shown by the fact that the slow reaction heat release peaks before the ignition case does.

The chemical reactions producing and consuming heat are very different (Fig. 10) for the slow and fast reaction cases. In the slow reaction case, the reactions that release energy involve weakly reactive species such as $\mathrm{HO}_{2}, \mathrm{H}_{2} \mathrm{O}_{2}$, and alkylperoxides. Although most of these reactions are highly exothermic, they proceed at a slow rate, keeping the energy release rate low. In the ignition case, the energy release is driven by two reactions: $\mathrm{H}+\mathrm{OH}+\mathrm{M} \Longleftrightarrow$ $\mathrm{H}_{2} \mathrm{O}+\mathrm{M}$ and $\mathrm{CO}+\mathrm{OH} \Longleftrightarrow \mathrm{CO}_{2}+\mathrm{H}$. These reactions produce the two main reaction products, $\mathrm{H}_{2} \mathrm{O}$ and $\mathrm{CO}_{2}$, and are very exothermic.

\subsection{Reaction pathway analysis}

The previous analyses demonstrates that the heating rate of the reactor controls the thermodynamic conditions which in turn control the chemical pathways. The dominant chemical pathways for each case are analyzed via detailed species rate of production and reaction pathway diagrams. 


\subsubsection{Radicals and atoms rate of production}

Rate of production analysis have been performed for $\mathrm{O}$ and $\mathrm{H}$ atoms, as well as, $\mathrm{OH}$ and $\mathrm{HO}_{2}$ radicals. Figure 11 presents the results obtained for both the slow reaction and the ignition cases for $\mathrm{H}$ and $\mathrm{OH}$. The dominant reaction responsible for the consumption of the $\mathrm{H}$ atoms during the slow reaction process is: $\mathrm{H}+\mathrm{O}_{2}(+\mathrm{M}) \Longleftrightarrow \mathrm{HO}_{2}(+\mathrm{M})$, forming less reactive $\mathrm{HO}_{2}$ radicals. Conversely, during the ignition process, $\mathrm{H}$ atoms are primarily consumed through the $\mathrm{H}+\mathrm{O}_{2} \Longleftrightarrow \mathrm{OH}+\mathrm{O}$ reaction, producing $\mathrm{OH}$ radicals.

In the slow reaction case, $\mathrm{OH}$ radicals are produced by $\mathrm{OH}$ elimination reactions and are mainly consumed by the following reactions:

(i) $\mathrm{CH}_{2} \mathrm{O}+\mathrm{OH} \Longleftrightarrow \mathrm{HCO}+\mathrm{H}_{2} \mathrm{O}$

(ii) $\mathrm{H}_{2} \mathrm{O}_{2}+\mathrm{CO}+\mathrm{OH} \Longleftrightarrow \mathrm{HOCHO}+\mathrm{HO}_{2}$

(iii) $\mathrm{CH}_{3} \mathrm{HCO}+\mathrm{OH} \Longleftrightarrow \mathrm{CH}_{3} \mathrm{CO}+\mathrm{H}_{2} \mathrm{O}$

(iv) $\mathrm{C}_{6} \mathrm{H}_{14}+\mathrm{OH} \Longleftrightarrow \mathrm{cC}_{6} \mathrm{H}_{13}+\mathrm{H}_{2} \mathrm{O}$.

where $\mathrm{cC}_{6} \mathrm{H}_{13}$ corresponds the to 3-hexyl radical. The analysis shows that no branching process occurs.

In the ignition case, $\mathrm{OH}$ radicals are rapidly produced by the following branching reactions:

(i) $\mathrm{H}+\mathrm{O}_{2} \Longleftrightarrow \mathrm{OH}+\mathrm{O}$

(ii) $\mathrm{O}+\mathrm{H}_{2} \Longleftrightarrow \mathrm{OH}+\mathrm{H}$

(iii) $\mathrm{H}_{2} \mathrm{O}+\mathrm{O} \Longleftrightarrow \mathrm{OH}+\mathrm{OH}$

and are consumed by the following exothermic reactions:

(i) $\mathrm{H}+\mathrm{OH}(+\mathrm{M}) \Longleftrightarrow \mathrm{H}_{2} \mathrm{O}(+\mathrm{M})$

(ii) $\mathrm{H}_{2}+\mathrm{OH} \Longleftrightarrow \mathrm{H}_{2} \mathrm{O}+\mathrm{H}$

(iii) $\mathrm{CO}+\mathrm{OH} \Longleftrightarrow \mathrm{CO}_{2}+\mathrm{H}$

The last two reactions also regenerate $\mathrm{H}$ atoms.

The consumption of $\mathrm{HO}_{2}$ radicals is driven by reactions which produce non-reactive species, mainly $\mathrm{H}_{2} \mathrm{O}_{2}$. In the fast reaction case, their consumption is driven by the $\mathrm{H}+\mathrm{HO}_{2} \Longleftrightarrow \mathrm{OH}+\mathrm{OH}$ reaction, which produces the very reactive $\mathrm{OH}$ radicals. Finally the $\mathrm{O}$ atoms take part in the chain branching process: $\mathrm{H}+\mathrm{O}_{2} \Longleftrightarrow \mathrm{OH}+\mathrm{O}$ and $\mathrm{O}+\mathrm{H}_{2} \Longleftrightarrow \mathrm{OH}+\mathrm{H}$, but only during the ignition event and not during the slow reaction. 


\subsubsection{Reaction pathway diagrams}

A $10 \%$ threshold is used for the element flux pathway diagrams in order to underline the most important pathways for both cases. The carbon element pathways for the two phases in the oxidation process are summarized in Figures 12 and 13. The first phase corresponds to the period where the temperature increases from 500 to $540 \mathrm{~K}$. In the slow reaction case, this period extends from 2350 to $2850 \mathrm{~s}$; for the fast reaction case, it extends from 1220 to $1430 \mathrm{~s}$. As shown in Figure 12 the main path for $n$-hexane consumption in both cases is the following:

(i) $\mathrm{H}$ abstraction by $\mathrm{OH}$ from the third carbon atom (C3),

(ii) $\mathrm{O}_{2}$ addition on carbon $\mathrm{C} 3$,

(iii) intramolecular $\mathrm{H}$ abstraction by $\mathrm{O}_{2}$ from the fifth carbon atom (C5),

(iv) second $\mathrm{O}_{2}$ addition on carbon $\mathrm{C} 5$,

(v) $\mathrm{OH}$ elimination-intramolecular $\mathrm{H}$ abstraction by $\mathrm{O}_{2}$ on carbon C3cetone formation on carbon $\mathrm{C} 3$.

During the slow reaction, a significant amount of the 5-hydroperoxy-hexan3 -one is decomposed into $\mathrm{OH}, \mathrm{CH}_{3} \mathrm{HCO}$, and $\mathrm{C}_{2} \mathrm{H}_{5} \mathrm{COCH}_{2}$. The last species is further converted through a series of reactions ultimately leading to $\mathrm{CH}_{2} \mathrm{O}$ and $\mathrm{C}_{2} \mathrm{H}_{5} \mathrm{O}$. During the first phase, these reaction rates are almost an order of magnitude higher in the slow reaction case as compared to the ignition case. This is explained by the significantly longer time the mixture spends under these conditions, allowing for an increase in $\mathrm{OH}$ concentration, and thus increasing the initiation rate.

During the second phase, additional pathways appear to be important. These are presented in Figure 13. For the slow reaction case, this phase extends from 2870 and $3100 \mathrm{~s}$ with an increase of temperature of $20 \mathrm{~K}$ to reach $560 \mathrm{~K}$. This phase is mainly characterized by successive:

(i) $\mathrm{CO}$ or $\mathrm{CO}_{2}$ elimination

(ii) $\mathrm{O}_{2}$ addition

(iii) $\mathrm{H}$ addition

(iv) $\mathrm{OH}$ elimination

The overall reaction rate remains the same throughout the entire process $\left(\sim 10^{-5} \mathrm{kmol} /\left(\mathrm{m}^{3} \mathrm{~s}\right)\right)$ and, at $3100 \mathrm{~s}, 95 \%$ of the initial $n$-hexane content is consumed.

For the fast reaction case, the second phase extends from 1430 to 1495 s, at which point ignition occurs, with an increase of temperature until 790 
$\mathrm{K}$. The reaction rates are on $\sim 100$ times higher than the reaction rates of the slow reaction case in this phase. During this phase, C-C bond rupture is favored over $\mathrm{O}_{2}$ addition. This process rapidly forms $\mathrm{CO}$ which then reacts with $\mathrm{OH}$ radicals to form $\mathrm{CO}_{2}$ and $\mathrm{H}$ atoms. This fast production of $\mathrm{H}$ atoms, further sustained by the temperature increase, induces an increase in the overall reaction rate through the chain branching reaction $\mathrm{H}+\mathrm{O}_{2} \Longleftrightarrow$ $\mathrm{OH}+\mathrm{O}$, and drives the ignition of the mixture. A large amount of $\mathrm{O}_{2}$ is consumed through addition reactions during the slow reaction. During the fast reaction case, $\mathrm{O}_{2}$ is still available in the gas phase for the branching process.

\subsection{Explosion Limits}

Figure 14 shows the simulated thermodynamic state trajectories, for the case with $\Phi=1.2$, along with the experimental explosion limits obtained for a $2.7 \% n$-hexane in air by Towsend et al. [28]. Figure 14 (a) illustrates the temporal evolution whereas Figure 14 (b) emphasizes the $n$-hexane concentration evolution. As shown in Figure 14 (a), in the slow reaction case the mixture spends a proportionally long time, several hundred seconds, at a temperature slightly below the auto-ignition temperature $498 \mathrm{~K}$. Due to the extended period the mixture spends at a temperature close to the autoignition temperature, more than $50 \%$ of reactants are consumed before entering the explosion region. This is shown in Figure 14 (b). Both Figures together show the importance of considering the evolution, in time and reaction progress, of a particular mixture rather than a simplified threshold point of view.

Analysis of the chemical composition during the slow reaction case shows that mixtures changes significantly from the original $\Phi=1.2(2.6 \%) n$-hexane air mixtures into a mix of other hydrocarbons, mainly oxygenated hydrocarbons. The ignition behavior of this mixture is no longer characterized by the explosion limit of the $2.7 \% n$-hexane air mixtures and no ignition is observed as the mixtures enters this ignition region. A slight acceleration of the reaction rate is observed just at the entrance of the explosion region. However, the energy release rate remains too low for ignition to occur and is balanced by the heat losses at the wall.

Conversely, the fast reaction case progresses much more rapidly, and the mixture quickly enters into the explosion region. In the fast reaction case, although a significant fraction of the reactants, around 10\%, is consumed be-

fore the mixture enters the explosion region, the composition is not modified 
enough to avoid explosion and the reactants consumption occurs according to a fast reaction driven by chain branching reactions.

Given the configuration of the experiment, the system has an intrinsic thermochemical feedback loop. By that we mean the dynamics of the system are controlled by the coupling of the thermodynamic state and the chemical kinetics. Depending on the heating rate, diverging chemical paths occur and in turn influence the evolution thermodynamic state.

\section{Concluding Remarks}

In the classical view of autoignition, a minimum temperature exists that leads to the ignition of a given fuel under specified conditions. It is known that the autoignition temperature depends on many parameters and the present study demonstrates that one of these, the rate at which the mixture is heated, greatly influences how the reaction progresses, and consequently whether the mixture ignites. Further, in some of the situations we have examined, we find that it is possible to consume all the fuel without an ignition event at a well-defined temperature.

For instance, increasing the heating rate of the vessel by a factor of 2 , from 4.25 to $11 \mathrm{~K} / \mathrm{min}$, produces an ignition event with a rapid pressure rise in a mixture that otherwise would have generated a slow reaction with no significant pressure rise. The same transition in behavior is shown for an increase in equivalence ratio from 1 to 1.2 . In the range investigated, the

minimum heating rate required for fast reactions decreases with increasing equivalence ratios.

The computations demonstrate that a model based on Semenov theory is capable of capturing the qualitative behavior of the oxidation event. By adding the heating rate, $\alpha$, to the classical Semenov model, we are able to reproduce the observed transition from a slow reaction case to an ignition case with increasing heating rate; with the necessity of determining the lumped heat transfer coefficient empirically.

The type of reaction that the mixture undergoes is a complex function of the mixture composition, thermochemical feedback loop, residence time, and heat transfer. Consequently, for sufficiently slow heating rates it is possible for the fuel to be completely consumed without any rapid pressure transient at temperatures above the classical autoignition value. The experimental results also indicate that the transitional heating rate is a function of the initial pressure and composition. 
The results presented here show that an assessment of safety should include factors such as the temperature, pressure, mixture composition, and heating rate rather than just a threshold temperature when considering autoignition. For instance, the temperatures at which the reactions occur are near the listed autoignition temperatures for the slow reaction case, but slightly below for the ignition case. These factors come into play both when designing a standard test procedure to determine fuel properties as well as assessing the safety of a particular engineering design.

The simulations show that the slow reaction and ignition behavior can be modeled correctly, however due to the complex chemical pathways and limited data on fuels like $n$-hexane at low temperatures it is difficult do predict the temperature at the onset of reaction to an accuracy better than $50 \mathrm{~K}$.

\section{Acknowledgement}

The work was carried out in the Explosion Dynamics Laboratory of the California Institute of Technology and was supported by The Boeing Company through a Strategic Research and Development Relationship Agreement CT-BA-GTA-1. The authors would like to thank Raza Akbar, Greg Rieker, Adrianus Indrat Aria, Bryan Hires, and David Gutschick for their help with the $2 \mathrm{f}$ detection, and John Ziegler and Jason Damazo for the help in refitting coefficients of the thermodynamic data to remove discontinuities. 
[1] ASTM, ASTM E659-78 (2005) Standard Test Method for Autoignition Temperature of Liquid Chemicals (2005).

[2] J. Colwell, A. Reza, Hot surface ignition of automotive and aviation fluids, Fire Technology 41 (2005) 105-123.

[3] M. J. Pilling (Ed.), Comprehensive Chemical Kinetics, Elsevier, 1997, Ch. 6 by J. F. Griffiths and C. Mohamed - Experimental and Numerical Studies of Oxidation Chemistry and Spontaneous Ignition Phenomena, pp. 545-650.

[4] H. C. Bailey and R. G. W. Norrish, The oxidation of hexane in the coolflame region, Proceedings of the Royal Society of London 212 (1110) (1952) 311-330.

[5] R. D. Wilk and N. P. Cernansky and R. S. Cohen, The Oxidation of Propane at Low and Transition Temperatures, Comb. Sci. and Tech 49 (1986) 41-78.

[6] J. F. Griffiths, P. A. Halford-Maw, D. J. Rose, Fundamental Features of Hydrocarbon Autoignition in a Rapid Compression Machine, Combustion and Flame 95 (3) (1993) 291-306.

[7] M. Ribaucour, R. Minetti, M. Carlier, L. R. Sochet, Autoignition at High-Pressure - Design, Construction and Test of a Rapid Compression Machine, Journal de Chimie Phsique et de Physico-Chimie Biologique 89 (11-12) (1992) 2127-2152.

[8] G. Vanhove, G. Petit, R. Minetti, Experimental study of the kinetic interactions in the low-temperature autoignition of hydrocarbon binary mixtures and a surrogate fuel, Combustion and Flame 145 (3) (2006) $521-532$.

[9] J. M. Kuchta, A. Bartkowiak, M. G. Zabetakis, Hot Surface Ignition Temperatures of Hydrocarbon Fuel Vapor-Air Mixtures, Journal of Chemical and Engineering Data 10 (3) (1965) 282-288.

[10] J. M. Kuchta, Investigation of Fire and Explosion Accidents in the Chemical, Mining, and Fuel-Related Industries, Bulletin 680, Bureau of Mines (1985). 
[11] C. R. Council, Handbook of Aviation Fuel Properties - CRC Report No. 530, Society of Automotive Engineers, Warrendale, PA (1983).

[12] A. E. Klingbeil and J. B. Jeffries and R. K. Hanson, Temperature- and pressure-dependent absorption cross sections of gaseous hydrocarbons at $3.39 \mu \mathrm{m}$, Measurements Science and Technology 17 (2006) 1950-1957.

[13] J. A. Drallmeier, Hydrocarbon absorption coefficients at the $3.39-\mu \mathrm{m}$ He-Ne laser transition, Applied Optics 42 (6) (2003) 979-982.

[14] D. N. Jaynes, B. H. Beam, Hydrocarbon gas absorption by a He-Ne laser beam at a $3.39 \mu \mathrm{m}$ wavelength, Applied Optics 8 (8) (1969) 1741-1742.

[15] T. Tsuboi, K. Inomata, Y. Tsunoda, A. Isobe, K. Nagaya, Lightabsorption by hydrocarbon molecules at $3.392 \mu \mathrm{m}$ of He-Ne Laser, Japanese Journal of Applied Physics Part 1 - Regular Papers Short Notes \& Review Papers 24 (1) (1985) 8-13.

[16] N. N. Semenov, Thermal theory of combustion and explosion, Progress of Physical Science 23 (1940).

[17] M. Allendorf, F. Maury, and F. Teyssandier (Ed.), D. G. Goodwin, in Chemical Vapor Depostion XVI and EUROCVD 14, Electrochemical Society Proceedings Series, Pennington, NJ (2003) 155.

URL code.google.com/p/cantera

[18] P. N. Brown, G. D. Byrne, A. C. Hindmarsh, Vode, a variable-coefficient ode solver, The SIAM Journal on Scientific and Statistical Computing 10 (1989) 1038-1051.

[19] H. Ramirez, K. Hadj-Ali, P. Dievart, G. Dayma, C. Togbe, G. Moreac, P. Dagaut, Oxidation of commercial and surrogate bio-diesel fuels (b30) in a jet-stirred reactor at elevated pressure: Experimental and modeling kinetic study, Proceedings of the Combustion Institute 33 (2011) 375382 .

[20] J. Simmie, Detailed chemical kinetic models for the combustion of hydrocarbon fuels, Progress in Energy and Combustion Science 29 (2003) 599-634. 
[21] H. Curran, P. Gaffuri, W. Pitz, C. Westbrook, W. Leppard, Autoignition chemistry of the hexane isomers: an experimental and kinetic modelling study., in: SAE International Fuels and Lubricants Meeting and Exposition, 1995.

[22] A. Burcat, E. Olchanski, C. Sokolinski, Kinetics of hexane combustion in a shock tube, Israel Journal of Chemistry 36 (1996) 313-320.

[23] V. P. Zhukov, V. A. Sechenov, A. Y. Starikovskii, Ignition delay times in lean $n$-hexane-air mixture at high pressures, Combustion and Flame 136 (2004) 257-259.

[24] A. P. Kelley, A. J. Smallbone, D. L. Zhu, C. K. Law, Laminar flame speeds of C5 to C8 n-alkanes at elevated pressures: Experimental determination, fuel similarity, and stretch sensitivity, Proceedings of the Combustion Institute 33 (2011) 963-970.

[25] T. J. Held, A. J. Marchese, F. L. Dryer, A semi-empirical reaction mechanism for n-heptane oxidation and pyrolysis, Combustion Science and Technology 123 (1997) 107-146.

[26] P. Dagaut, M. Reuillon, M. Cathonnet, Experimental study of the oxidation of n-heptane in a jet stirred reactor from low to high temperature and pressures up to 40 atm, Combustion and Flame 101 (1995) 132-140.

[27] F. M. White, Heat Transfer, Addison-Wesley, Boston, MA, 1984.

[28] G. P. Kane, E. A. C. Chamberlain and D. T. A. Townend, The Spontaneous Ignition under Pressure of the Simpler Aliphatic Hydrocarbons, Alcohols, and Aldehydes, Journal of Chemical Society (1937) 436-443.

[29] L. C. Philippe, R. K. Hanson, Laser diode wavelength-modulation spectroscopy for simultaneous measurement of temperature, pressure, and velocity in shock-heated oxygen flows, Applied Optics 32 (1993) 60906103 .

[30] M. Kroll, J. A. McClintock, O. Ollinger, Measurement of gaseous oxygen using diode laser spectroscopy, Applied Physics Letters 51 (1987) 14651467. 
[31] G. B. Rieker, J. B. Jeffries, R. K. Hanson, Calibration-free wavelengthmodulation spectroscopy for measurements of gas temperature and concentration in harsh environments, Applied Optics 48 (29) (2009) 55465560 .

[32] P. A. Boettcher, R. Akbar, J. E. Shepherd, Low temperature oxidation of hexane, in: Proceedings of the Fall Meeting of the Western States Section of the Combustion Institute (2009) 1-14.

[33] J. Reird, D. Labrie, 2nd-harmonic detection with tunable diode-lasers comparison of experiment and theory, Applied Physics B-Photophysics and Laser Chemistry 26 (3) (1981) 203-210.

[34] R. Mével, P. A. Boettcher, and J. E. Shepherd, Absorption cross section at $3.39 \mu \mathrm{m}$ of alkanes, aromatics and substituted hydrocarbons, Chemical Physics Letters, submitted. 


\section{Appendix: Oxygen concentration measurements}

\section{Introduction}

In addition to the fuel concentration measurements, an attempt has been made to spectroscopically monitor the molecular oxygen concentration during the heating rate experiments. Since transitions in the A band near 760 $\mathrm{nm}$ are spin forbidden, direct absorption measurements of $\mathrm{O}_{2}$ is complicated due to the very weak absorption cross sections [29]. One method for overcoming this limitation is the use of a derivative technique of spectroscopy with second harmonic (2f) detection as demonstrated by Kroll et al. [30], Philippe and Hanson [29], and Rieker and Hanson [31]. The 2f technique utilizes a high frequency modulation of the output wavelength of a laser diode as its wavelength is scanned across the absorption line.

First, the basic principles of the technique are explained. Second, the experimental setup is described. Third, the calibration procedure is presented. Finally, the experimental results are detailed.

\section{Basic principles}

A comprehensive description of the laser diode wavelength-modulation spectroscopy technique with second harmonic detection can be found in [32]. Only the main steps are highlighted in the following.

The attenuation of a laser beam's intensity, $I(\nu)$, as it travels through an absorbing medium is described by the Beer-Lambert law:

$$
I(\nu)=I_{0}(\nu) \exp (-\alpha(\nu) L),
$$

where $I_{0}(\nu)$ is the incident laser beam intensity, $\alpha(\nu)$ is the absorption coefficient, $L$ is the path length and $\nu$ is the light frequency.

For weak absorption coefficients, the Beer-Lambert law can be approximated by:

$$
\left.I(\nu) \approx I_{0}(\nu)(1-\alpha(\nu) L)\right) .
$$

Applying a modulation of frequency $\omega$ to the diode input current induces the modulation of the diode output light wavelength such that:

$$
\nu(t)=\bar{\nu}+a \cos (\omega t),
$$

where $t$ is the time, $\bar{\nu}$ the mean frequency and $a$ the modulation amplitude.

A carrier signal with a low frequency relative to the modulation frequency is added to the modulation signal in order to scan across the absorption 
line. For carrier signal with low amplitude, the incident laser beam intensity variations are small. The transmitted light intensity can thus be written as:

$$
I(\nu)=I_{0}[1-\alpha(\bar{\nu}+a \cos (\omega t)) L] .
$$

Expanding the time dependent part in a Taylor series and collecting the terms of same frequency gives the following expression as formulated by Reid and Labrie [33]:

$$
\alpha(\bar{\nu}+a \cos (\omega t))=\sum_{n=0}^{\infty} H_{n}(\bar{\nu}) \cos (n \omega t)
$$

where:

$$
H_{n}(\bar{\nu})=\frac{2^{1-n}}{n !} \alpha^{n}{\frac{d^{n} \alpha(\nu)}{d \nu^{n}}}_{\nu=\bar{\nu}}, n \geq 1,
$$

with $n$ the harmonic order. A lock-in amplifier can then be used to selectively amplify the second harmonic term. Assuming a Lorentzian line shape for the absorption line and evaluating at $\nu=\nu_{0}=\bar{\nu}$, the second derivative of the absorption coefficient can be expressed as:

$$
\left.\frac{d^{2} \alpha(\nu)}{d \nu^{2}}\right|_{\nu=\nu_{0}=\bar{\nu}}=-\frac{2 \alpha_{0}}{\Delta \nu^{2}}
$$

For a prefect gas, the second derivative of the signal intensity can be linked to the oxygen partial pressure by the following:

$$
\left.\frac{d^{2} I}{d \nu^{2}}\right|_{\nu=\nu_{0}=\tilde{\nu}}=\frac{2 I_{0} L \sigma_{\nu}}{R T \Delta \nu^{2}} P_{O 2} \exp \left(-\frac{\sigma_{\nu} L}{R T} P_{O 2}\right)=C_{1} P_{O 2} \exp \left(-C_{2} P_{O 2}\right)
$$

where $\sigma_{\nu}$ is the absorption cross section, $C_{1}$ and $C_{2}$ are constants obtained through a calibration procedure.

\section{Experimental setup and calibration procedure}

The experimental arrangement is shown in Figure 15. It consists of a signal generator, a summing amplifier, a laser diode with current and temperature controllers, a lock-in amplifier, a low noise preamplifier with bandpass filter, and a waveform recorder. The signal generator is used to create a sawtoothlike carrier signal with a frequency of $80 \mathrm{~Hz}$ and an amplitude of $\sim 100 \mathrm{~mA}$. This signal scans across the absorption line. The second signal, the sine wave, is generated by the lock-in amplifier's internal signal generator with a 
frequency of $23.5 \mathrm{kHz}$ and an amplitude of $4 \mathrm{~mA}$. These signals are summed and then sent to the laser diode current controller. Both the sine wave signal and the transmitted laser diode beam are collected by the lock-in detector. The resulting signal is then filtered and recorded by the waveform recorder.

The height of the $2 \mathrm{f}$ peak is calibrated against the partial pressure of oxygen. Figure 16 shows that the peak height varies linearly with the amount of oxygen as predicted from Equation 13 for the range of oxygen concentrations investigated. For calibration, the vessel is first evacuated to below $10 \mathrm{~Pa}$ and then filled with increasing amounts of oxygen. The second calibration was performed by first filling the vessel with $67 \mathrm{kPa}$ of $\mathrm{N}_{2}$ and then mixing the oxygen with the nitrogen in increasing steps. The linear constant is reduced when nitrogen is added, which is expected due to the effect of pressure broadening. Also indicated in Figure 16 is the uncertainty in the calibration measurement. This uncertainty is strictly based on the evaluation of the standard deviation about the mean of the time series data acquired over the measurement interval, typically 30 seconds. The uncertainty in the pressure is less than the indicated symbol size. The calibration was performed at room temperature.

\section{Application to oxygen measurements}

The measurement of oxygen concentration was only implemented successfully once during the course of this investigation. The experimental technique has proven to be extremely sensitive the variations in the optical path. The experimental procedure of heating the vessel from room temperature over a very long time period causes the glass vessel to expand. This produces both an etalon effect and beam steering, which we were only able to correct for by using a non-reactive mixture for one data set. Figure 17 shows the consumption of the oxygen and fuel for a fuel rich mixture $(\Phi=1.2)$ at a low initial pressure $\left(P_{0}=26.67 \mathrm{kPa}\right)$ heated at a $11.2 \mathrm{~K} / \mathrm{min}$. The measurements show consumption of the fuel and oxygen at the same time, which agrees with the simulation results of the slow reaction shown in Figure 8 (a). This result agrees with the overall trends shown in Figure 4, which show that reducing pressure, heating rate, or equivalence ratio sufficiently in the range investigated leads to a slow reaction of the mixture instead of ignition.

For future experiments, the limitations shown here could be addressed in several ways. First, the impact of the optical path variations could be reduced by increasing the test cell dimension or isolating the windows mechanically from the test cell. Additionally, the sensitivity of the measurements could 
be increased by evacuating or nitrogen flushing the laser beam path outside the test cell, which would avoid perturbations due the oxygen contained in air. Finally, the overall experimental procedure could be adapted to start the temperature ramp at a higher temperature, reducing the total temperature change. 


\section{List of Figures}

1 Schematic of the experimental set-up (all dimensions are in $\mathrm{cm}$ ).

2 Slow reaction of a fuel rich $(\Phi=1.2) n$-hexane/air mixture at an initial pressure of $101 \mathrm{kPa}$ heated at $4.25 \mathrm{~K}$ per minute. . .

3 Ignition of a fuel rich $(\Phi=1.2) n$-hexane/air mixture at an initial pressure of $101 \mathrm{kPa}$ heated at $11 \mathrm{~K}$ per minute. . . . . .

4 Experimental results as a function of total pressure, temperature ramp rate, and equivalence ratio. . . . . . . . . . . .

5 Comparison of shock tube experimental data to the predictions of the Ramirez model for $n$-hexane-oxygen-argon mixture. (a) data of Burcat et al. [22] (b) data of Zhukov et al. [23].

6 Comparison of flow and jet-stirred reactor experimental data to the predictions of the Ramirez model for n-heptane-oxygennitrogen mixtures. (a) flow reactor data from Held et al. [25]. Conditions: $\Phi=0.79 ; T=930 \mathrm{~K} ; P=303 \mathrm{kPa} ; X_{N 2}=$ 0.9831. (b) jet-stirred reactor data from Dagaut et al. [26], Conditions: $\Phi=1$; Residence time $=1 \mathrm{~s} ; P=1010 \mathrm{kPa} ; X_{N 2}$ $=0.988$.

$7 \quad$ Simulated temperature and pressure profiles for a $n$-hexaneair mixture for two different heating rates. Conditions: $\Phi=$

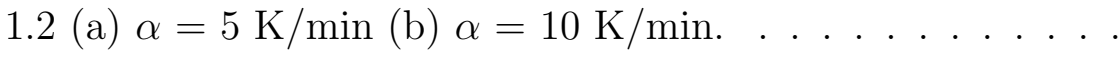

8 Simulated species profiles for a $n$-hexane-air mixture for two different heating rates. Conditions: $\Phi=1.2$ (a) $\alpha=5 \mathrm{~K} / \mathrm{min}$ (b) $\alpha=10 \mathrm{~K} / \mathrm{min}$.

9 Chemical heat production and heat loss rates for a $n$-hexaneair mixture for two different heating rates. Conditions: $\Phi=$ $1.2 ; \alpha=5 \mathrm{~K} / \mathrm{min}$ and $\alpha=10 \mathrm{~K} / \mathrm{min}$ (Ignition - Ign, Slow Reaction - SR). . . . . . . . . . . . . .

10 Net energy release rate during (a) slow reaction and (b) ignition.

11 Rate of production of $\mathrm{H}$ atoms and $\mathrm{OH}$ radicals for a $\Phi=1.2$ $n$-hexane-air mixture and two different heating rates: (a) and (b), $\alpha=5 \mathrm{~K} / \mathrm{min}$; (c) and (d), $\alpha=10 \mathrm{~K} / \mathrm{min} . . . . . .$. 
12 Carbon reaction pathways during the first phase of a $n$-hexaneair mixture oxidation for two heating rates. Conditions: $\Phi=$ $1.2 ; \alpha=5$ and $10 \mathrm{~K} / \mathrm{min}$. Black arrows: common pathways. Blue arrows: additional pathways observed during the slow reaction. The first phase extends from 2350 to $2850 \mathrm{~s}$ for the slow reaction and from 1220 to $1430 \mathrm{~s}$ for the fast reaction. .

13 Carbon reaction pathways during the second phase of a $n$ hexane-air mixture oxidation for two heating rates. The second phase extends from 2850 to $3100 \mathrm{~s}$ for the slow reaction and from from 1430 to $1495 \mathrm{~s}$ for the fast reaction. . . . . .

14 Thermodynamic state trajectories along with the explosion limits [28] for a $n$-hexane-air mixture with different heating rates. Conditions: $\Phi=1.2 ; \alpha=5$ and $10 \mathrm{~K} / \mathrm{min}$; (a): temporal evolution (500 s elapsed time between points). (b): $n$ hexane percentage consumed in the boxed region of (a). . . .

15 Schematic of the experimental setup for molecular oxygen measurements. . . . . . . . . . . . . . . . .

16 Calibration curve, second harmonic peak height as a function of molecular oxygen partial pressure with $\pm \sigma$ uncertainty bars $\left(\mathrm{O}_{2}\right.$ only and $\mathrm{O}_{2}$ with $67 \mathrm{kPa} \mathrm{N}_{2}$ dilution $) \ldots \ldots \ldots$

17 Measurement of the molecular oxygen and fuel concentration during a slow reaction for a $n$-hexane/air mixture. Conditions: $P_{0}=26.67 \mathrm{kPa}, \Phi=1.2, \alpha=11.2 \mathrm{~K} / \mathrm{min} \ldots \ldots \ldots$ 


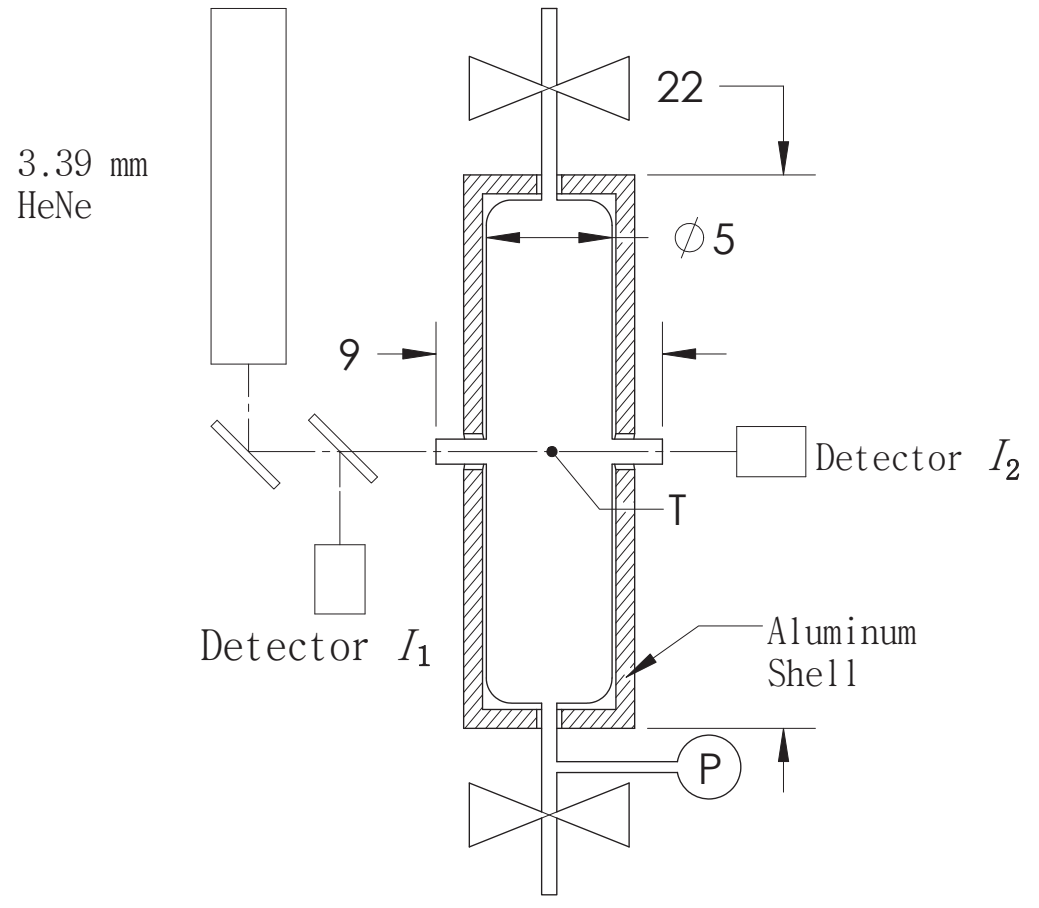

Figure 1: Schematic of the experimental set-up (all dimensions are in $\mathrm{cm}$ ) 


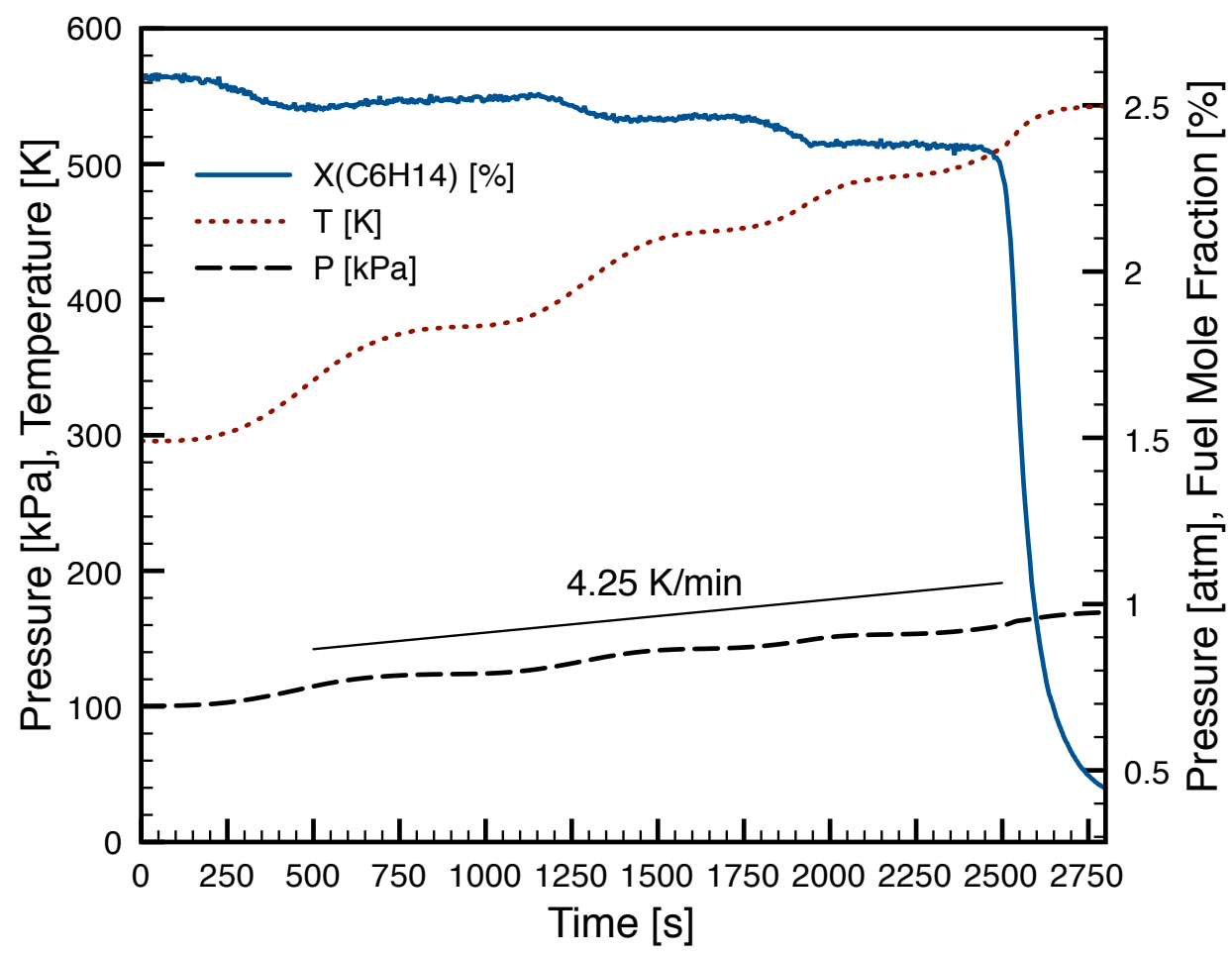

Figure 2: Slow reaction of a fuel rich $(\Phi=1.2) n$-hexane/air mixture at an initial pressure of $101 \mathrm{kPa}$ heated at $4.25 \mathrm{~K}$ per minute 


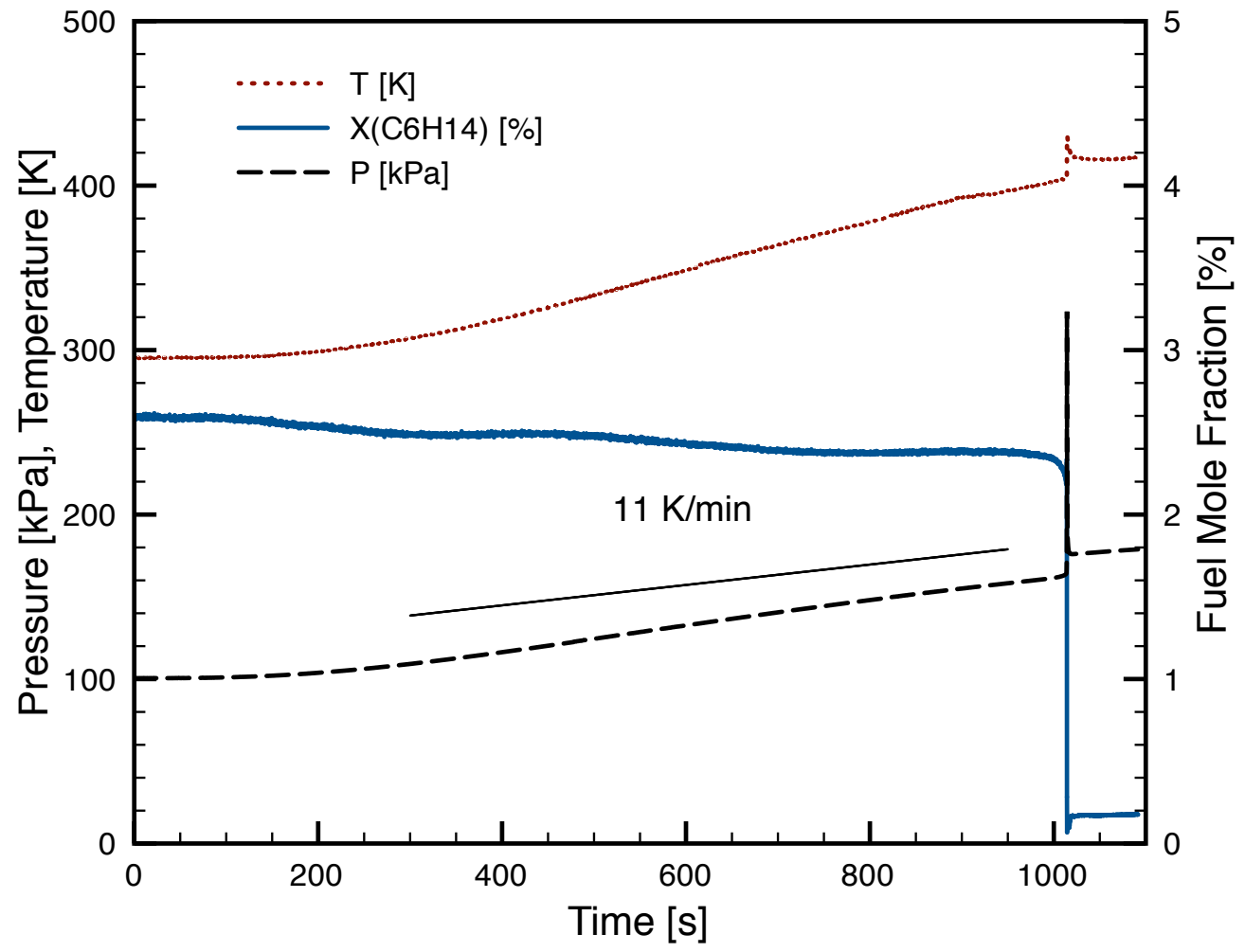

Figure 3: Ignition of a fuel rich $(\Phi=1.2) n$-hexane/air mixture at an initial pressure of $101 \mathrm{kPa}$ heated at $11 \mathrm{~K}$ per minute 


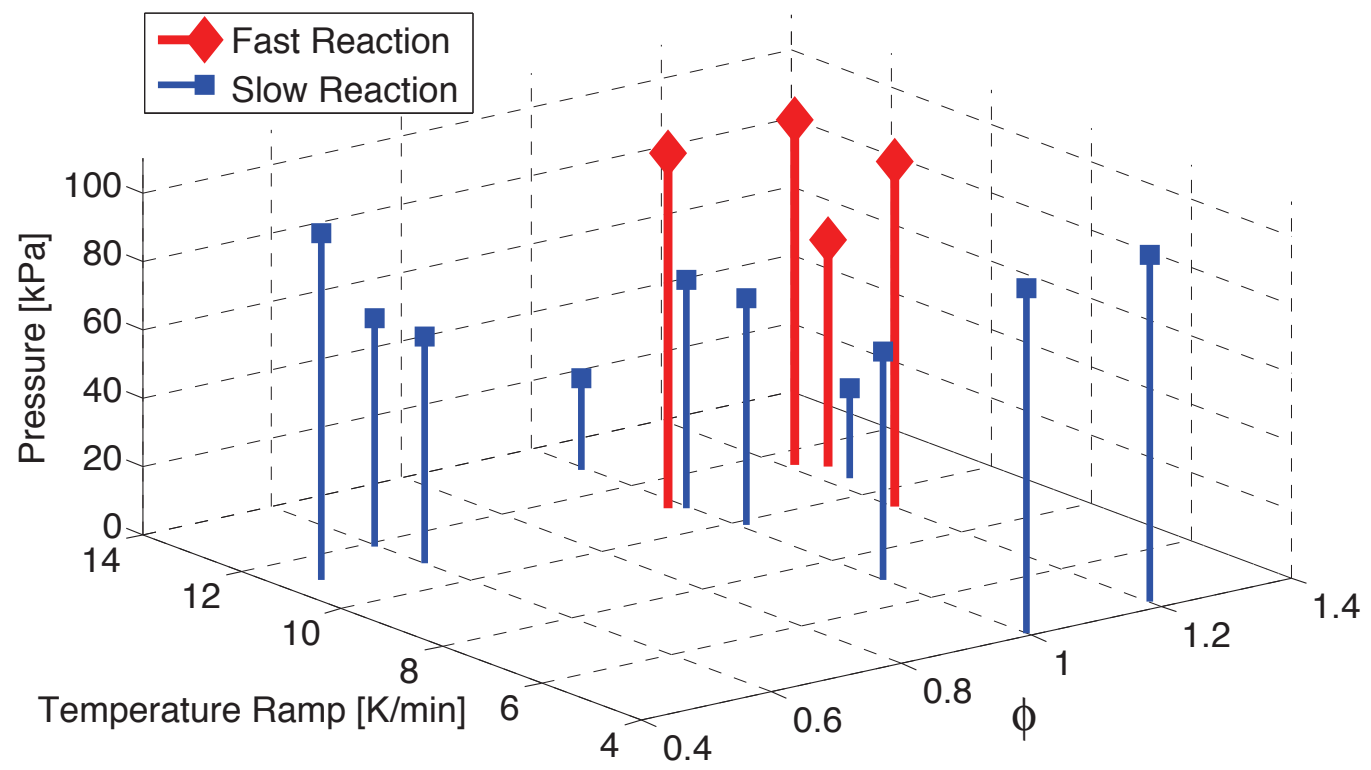

Figure 4: Experimental results as a function of total pressure, temperature ramp rate, and equivalence ratio

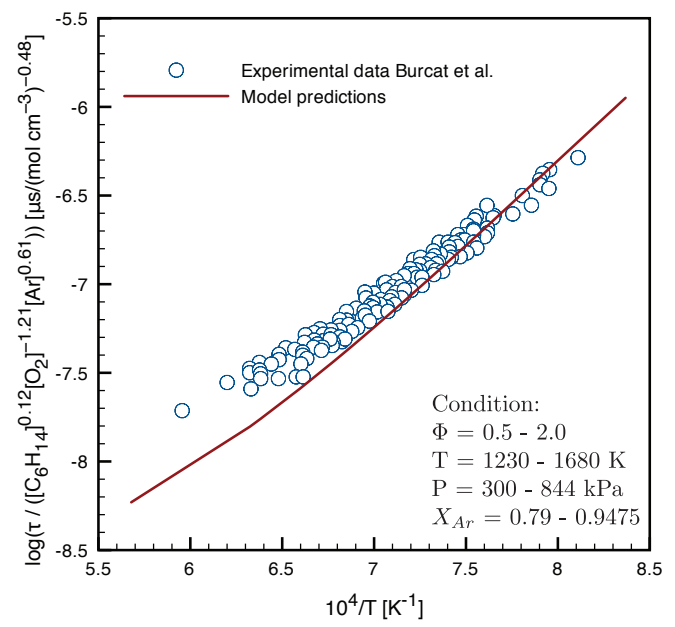

(a)

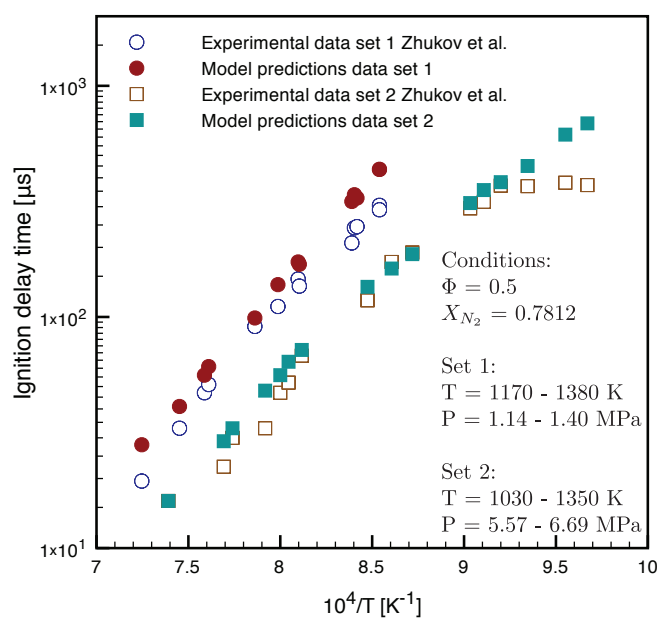

(b)

Figure 5: Comparison of shock tube experimental data to the predictions of the Ramirez model for $n$-hexane-oxygen-argon mixture. (a) data of Burcat et al. [22] (b) data of Zhukov et al. [23] 


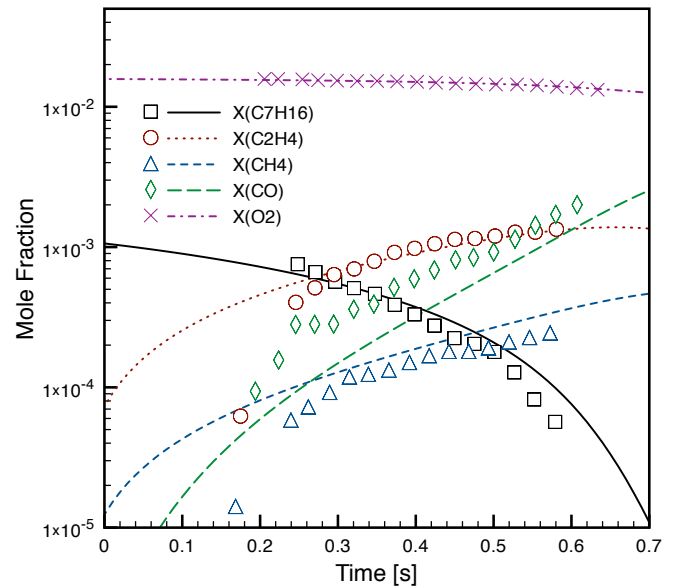

(a)

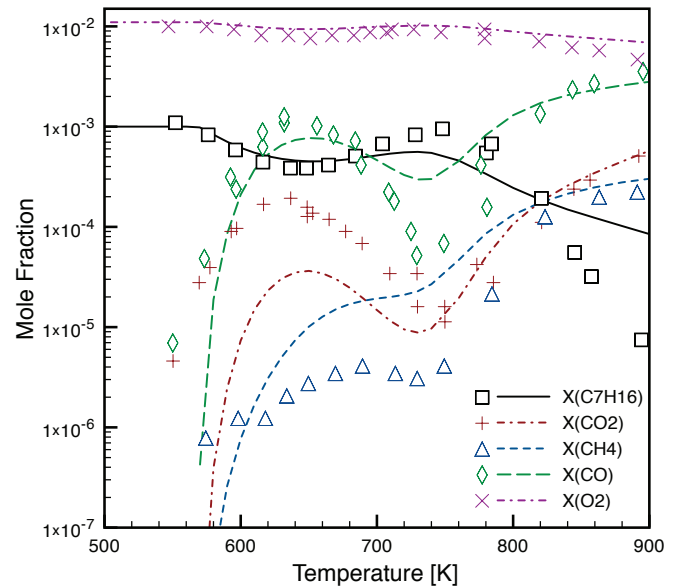

(b)

Figure 6: Comparison of flow and jet-stirred reactor experimental data to the predictions of the Ramirez model for n-heptane-oxygen-nitrogen mixtures. (a) flow reactor data from Held et al. [25]. Conditions: $\Phi=0.79 ; T=930 \mathrm{~K} ; P=303 \mathrm{kPa} ; X_{N 2}=0.9831$. (b) jet-stirred reactor data from Dagaut et al. [26], Conditions: $\Phi=1$; Residence time $=1 \mathrm{~s}$; $P=1010 \mathrm{kPa} ; X_{N 2}=0.988$ 


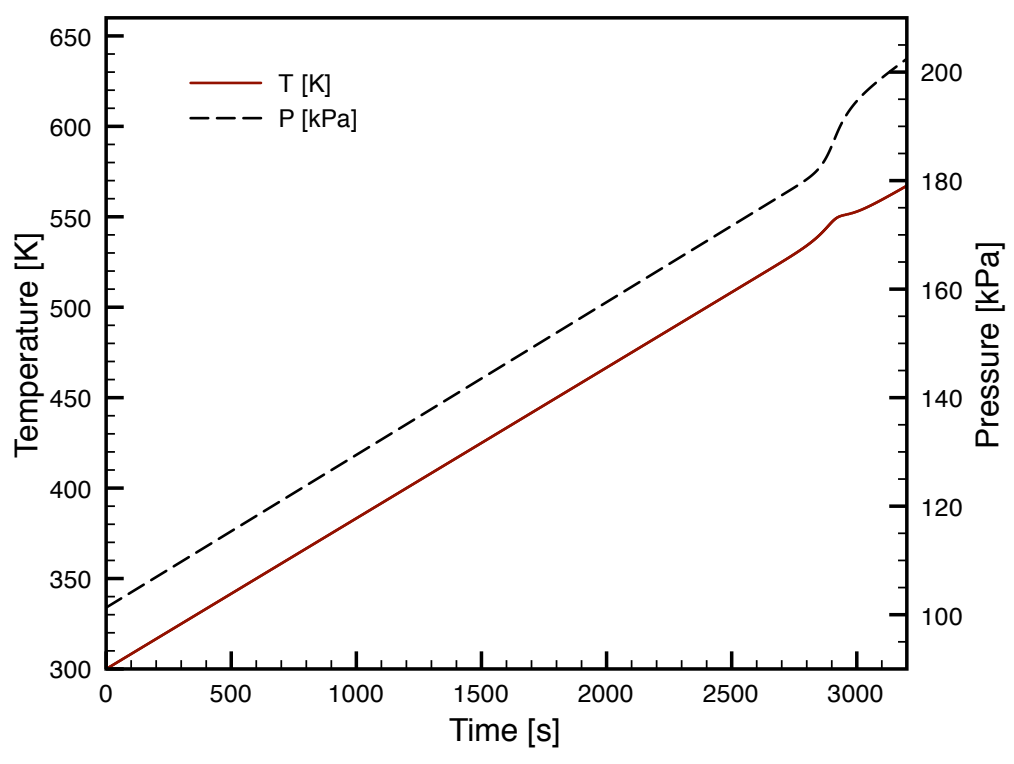

(a)

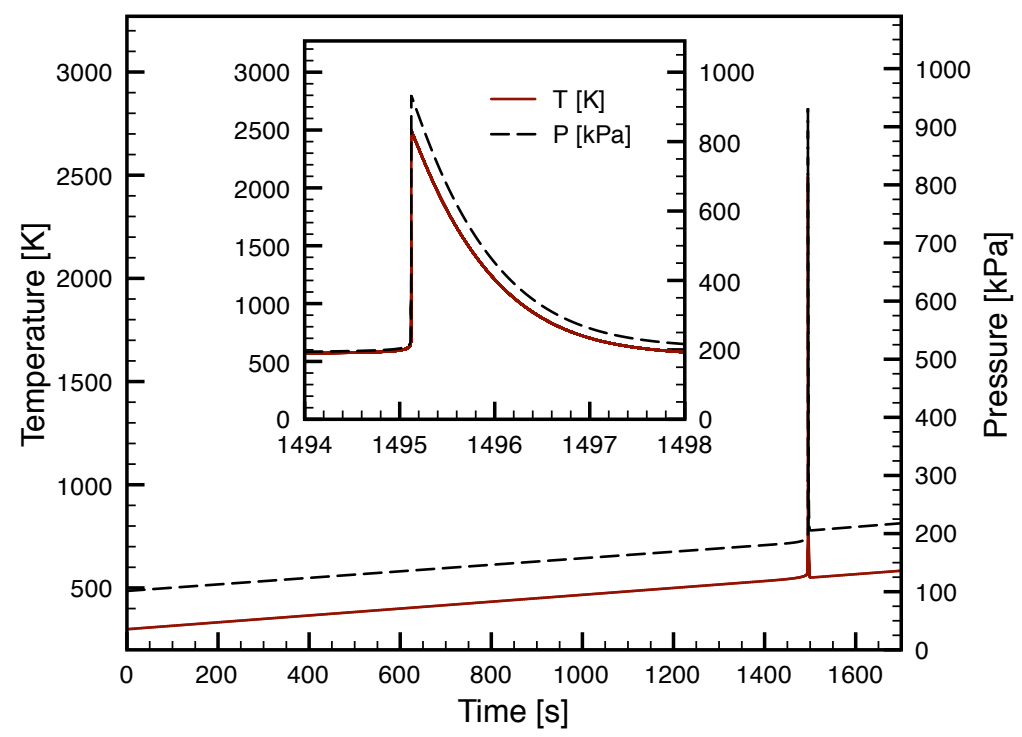

(b)

Figure 7: Simulated temperature and pressure profiles for a $n$-hexane-air mixture for two different heating rates. Conditions: $\Phi=1.2$ (a) $\alpha=5 \mathrm{~K} / \mathrm{min}$ (b) $\alpha=10 \mathrm{~K} / \mathrm{min}$ 


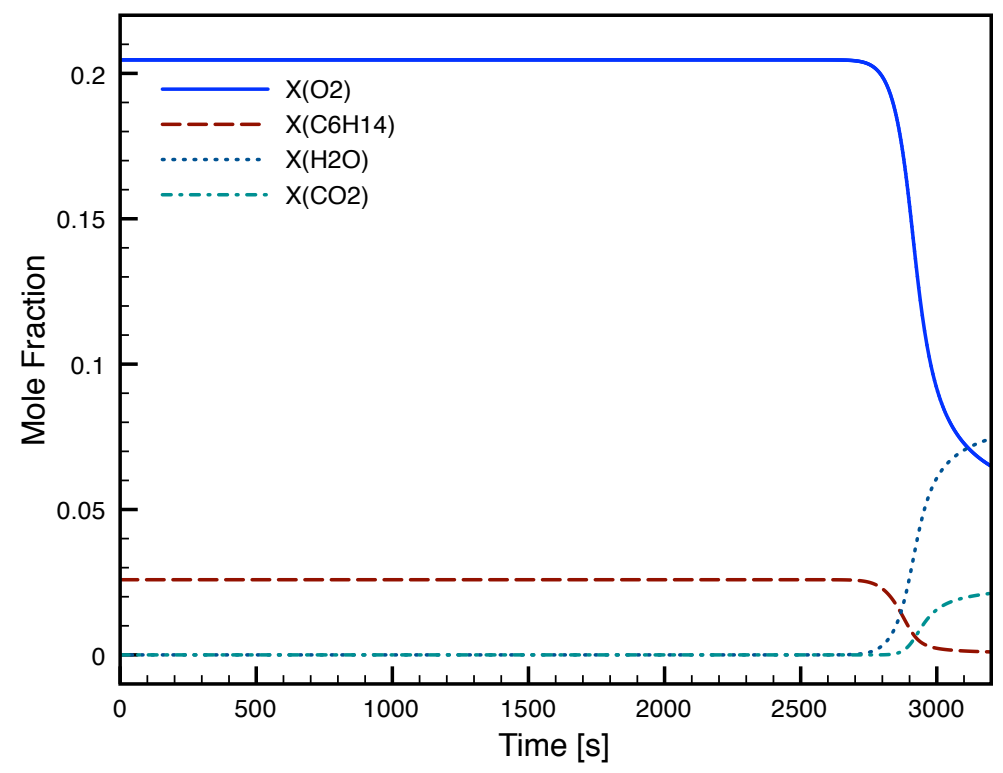

(a)

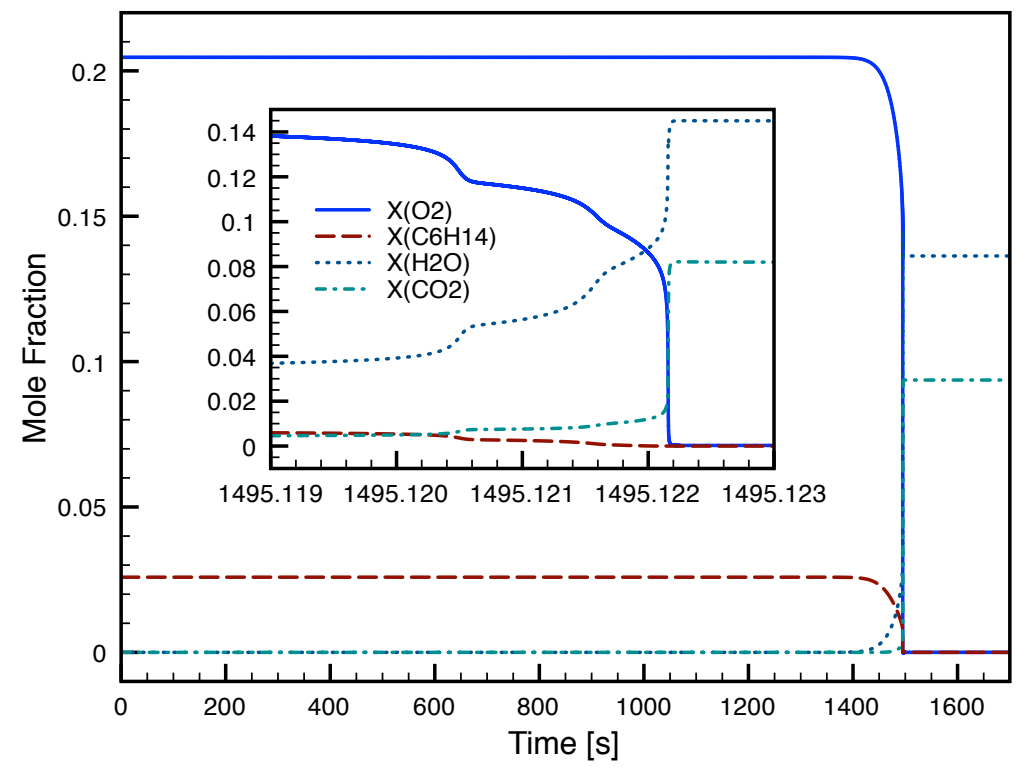

(b)

Figure 8: Simulated species profiles for a $n$-hexane-air mixture for two different heating rates. Conditions: $\Phi=1.2$ (a) $\alpha=5 \mathrm{~K} / \mathrm{min}$ (b) $\alpha=10 \mathrm{~K} / \mathrm{min}$ 


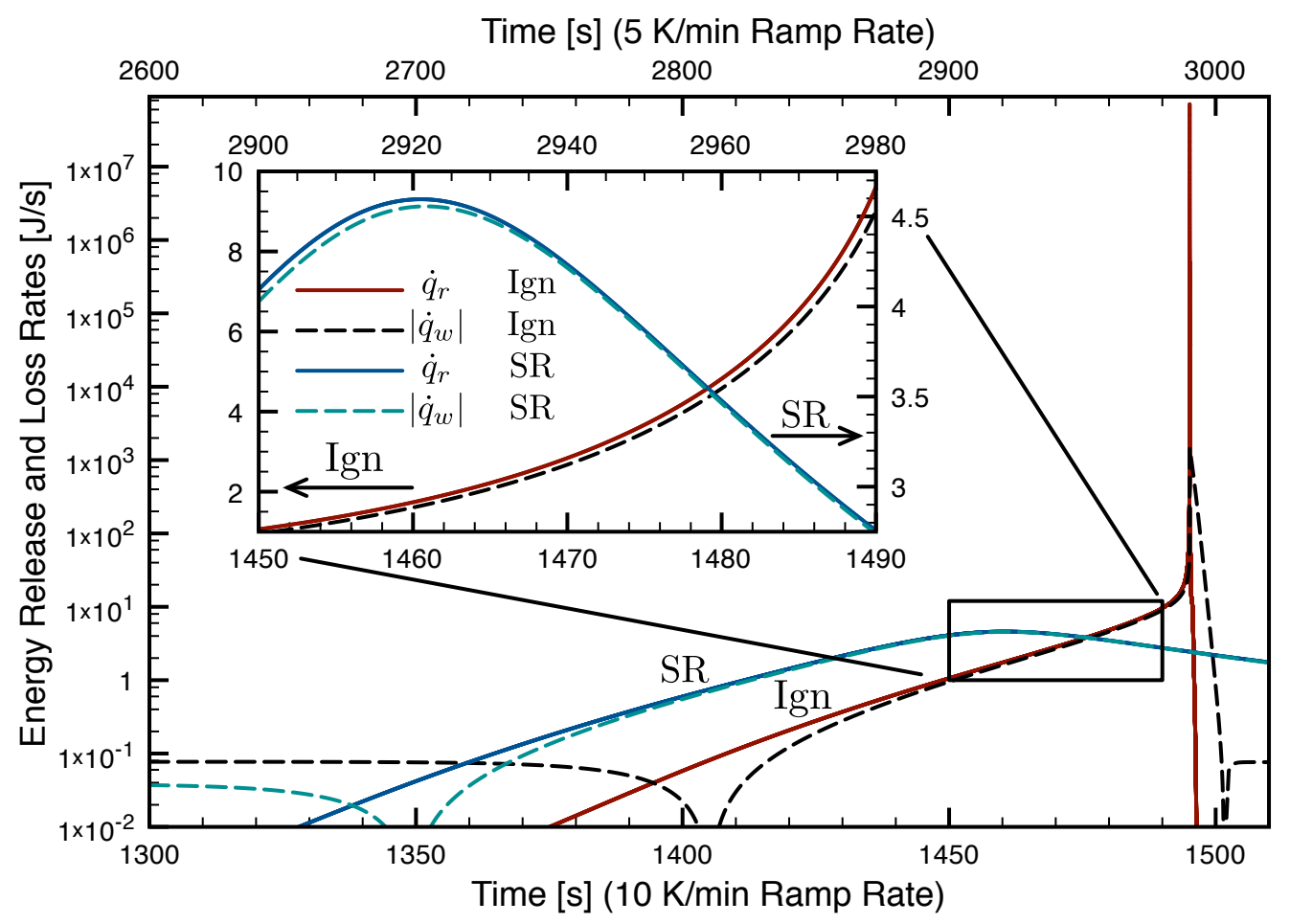

Figure 9: Chemical heat production and heat loss rates for a $n$-hexane-air mixture for two different heating rates. Conditions: $\Phi=1.2 ; \alpha=5 \mathrm{~K} / \mathrm{min}$ and $\alpha=10 \mathrm{~K} / \mathrm{min}$ (Ignition Ign, Slow Reaction - SR) 


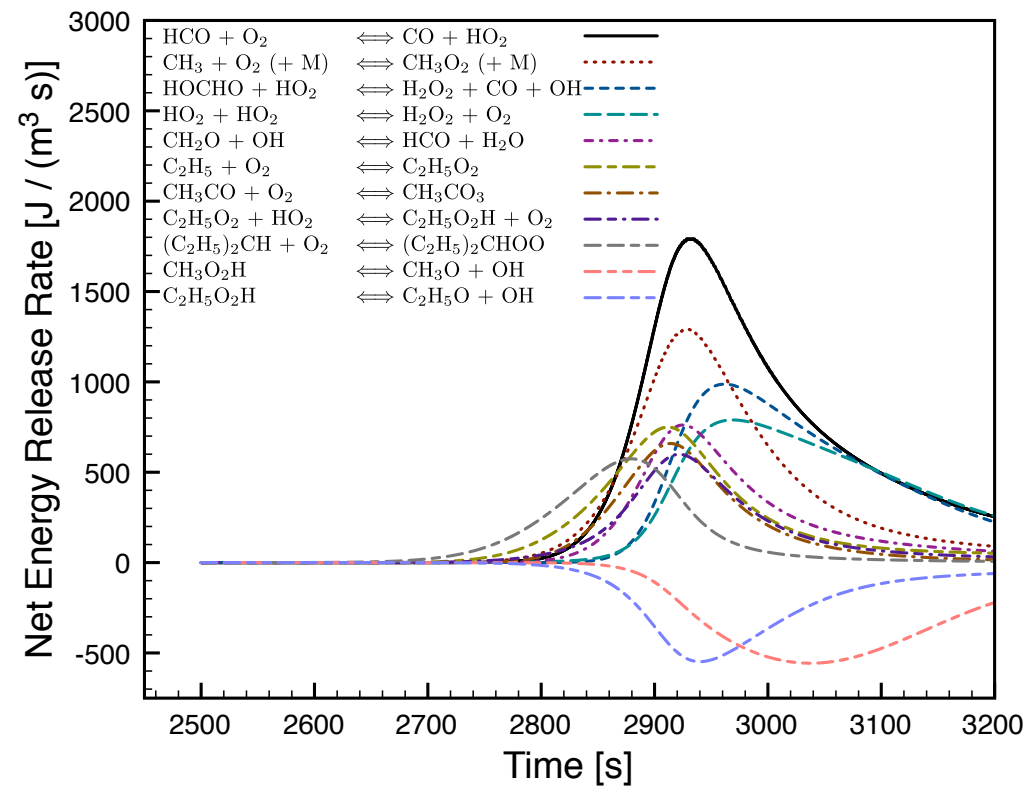

(a)

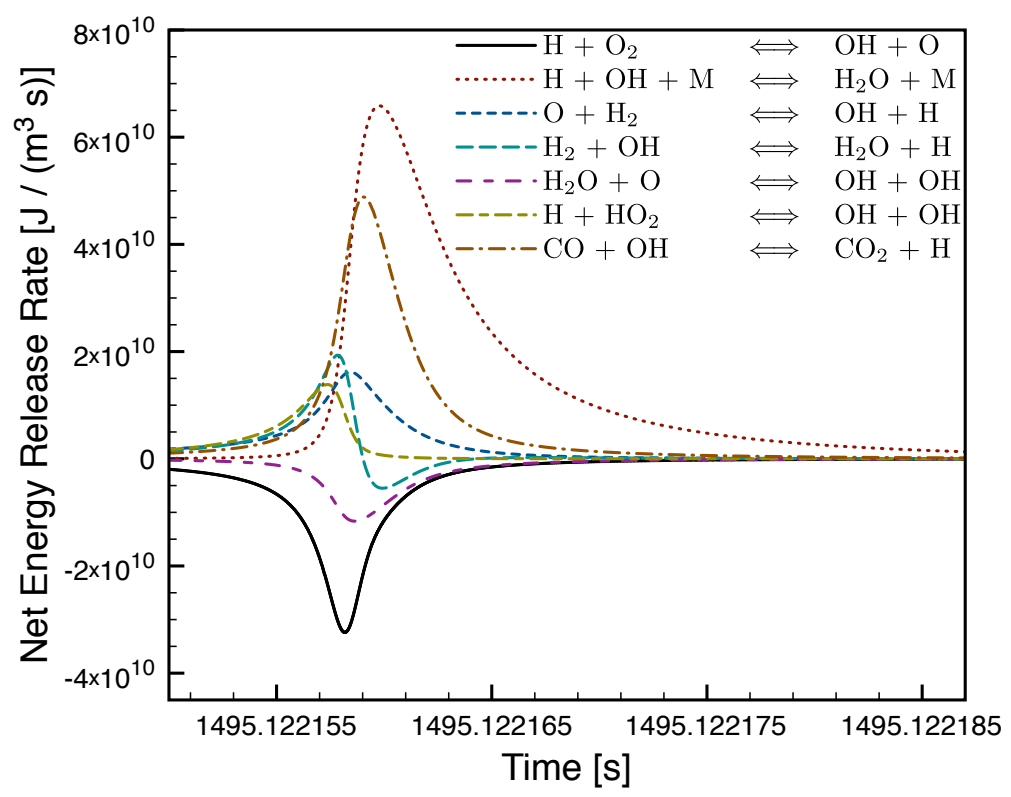

(b)

Figure 10: Net energy release rate during (a) slow reaction and (b) ignition 


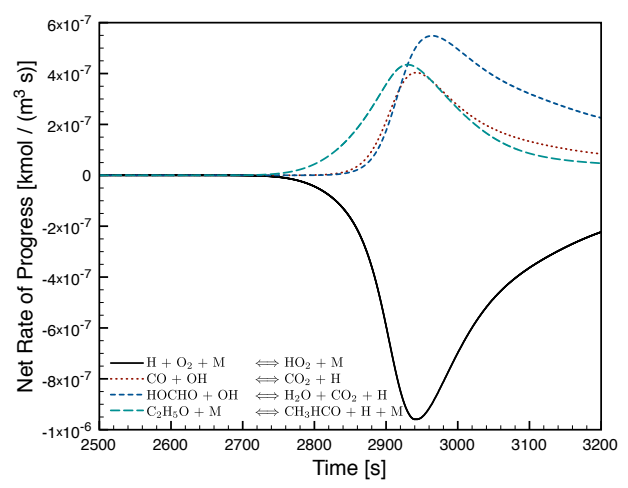

(a) $\mathrm{H}$ atoms $(\alpha=5 \mathrm{~K} / \mathrm{min})$

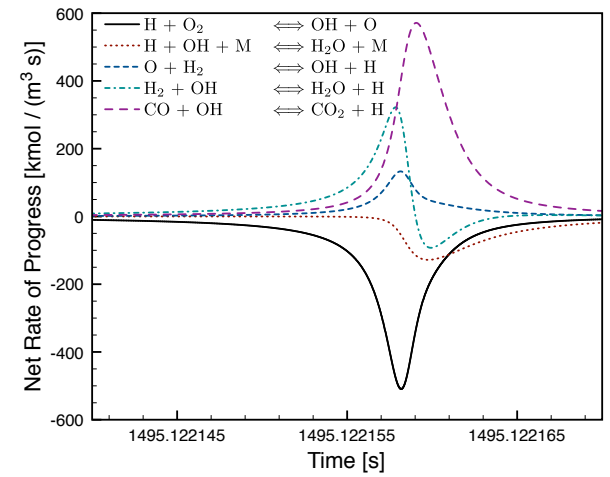

(c) $\mathrm{H}$ atoms $(\alpha=10 \mathrm{~K} / \mathrm{min})$

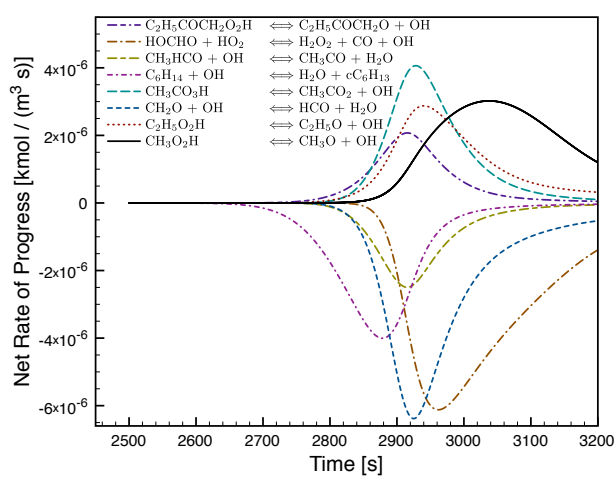

(b) $\mathrm{OH}$ radicals $(\alpha=5 \mathrm{~K} / \mathrm{min})$

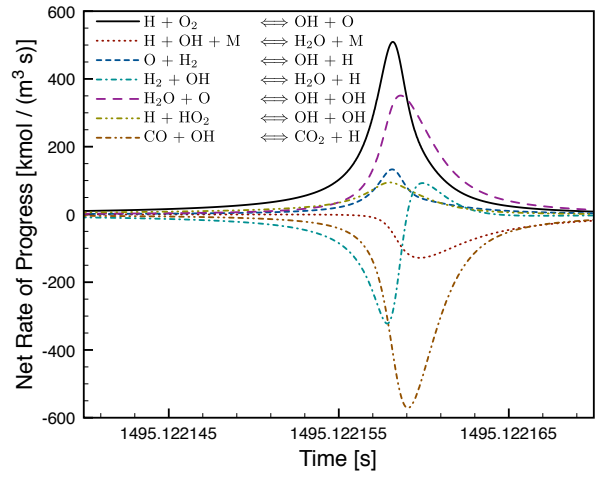

(d) $\mathrm{OH}$ radicals $(\alpha=10 \mathrm{~K} / \mathrm{min})$

Figure 11: Rate of production of $\mathrm{H}$ atoms and $\mathrm{OH}$ radicals for a $\Phi=1.2 n$-hexane-air mixture and two different heating rates: (a) and (b), $\alpha=5 \mathrm{~K} / \mathrm{min}$; (c) and (d), $\alpha=10$ $\mathrm{K} / \mathrm{min}$ 


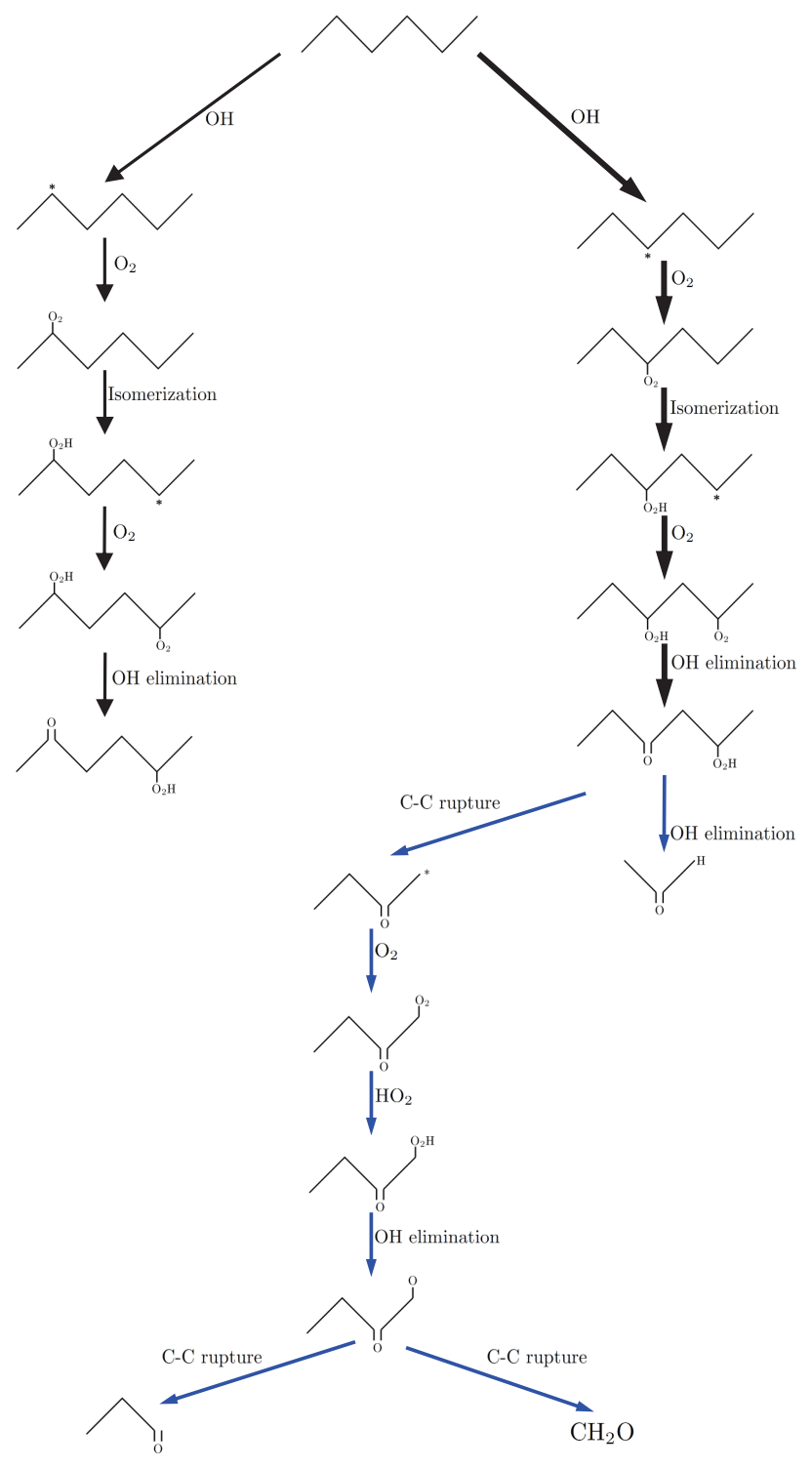

Figure 12: Carbon reaction pathways during the first phase of a $n$-hexane-air mixture oxidation for two heating rates. Conditions: $\Phi=1.2 ; \alpha=5$ and $10 \mathrm{~K} / \mathrm{min}$. Black arrows: common pathways. Blue arrows: additional pathways observed during the slow reaction. The first phase extends from 2350 to $2850 \mathrm{~s}$ for the slow reaction and from 1220 to 1430 $\mathrm{s}$ for the fast reaction. 


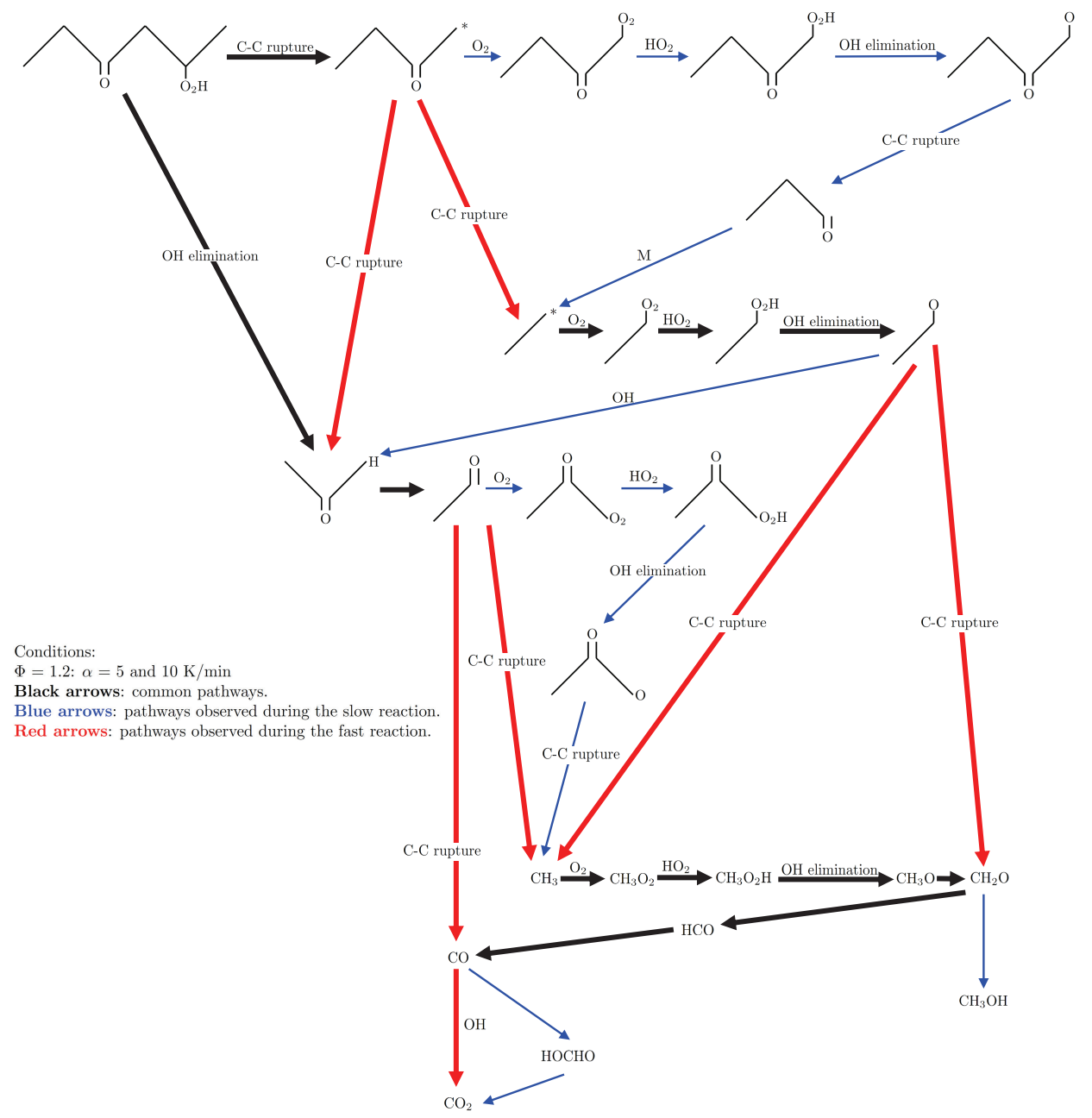

Figure 13: Carbon reaction pathways during the second phase of a $n$-hexane-air mixture oxidation for two heating rates. The second phase extends from 2850 to $3100 \mathrm{~s}$ for the slow reaction and from from 1430 to $1495 \mathrm{~s}$ for the fast reaction. 


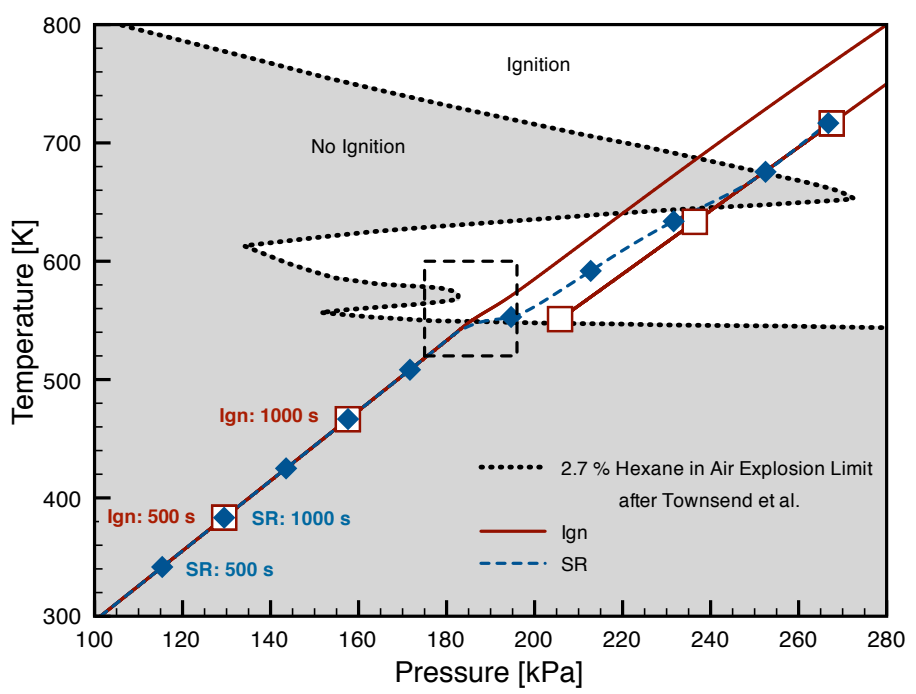

(a)

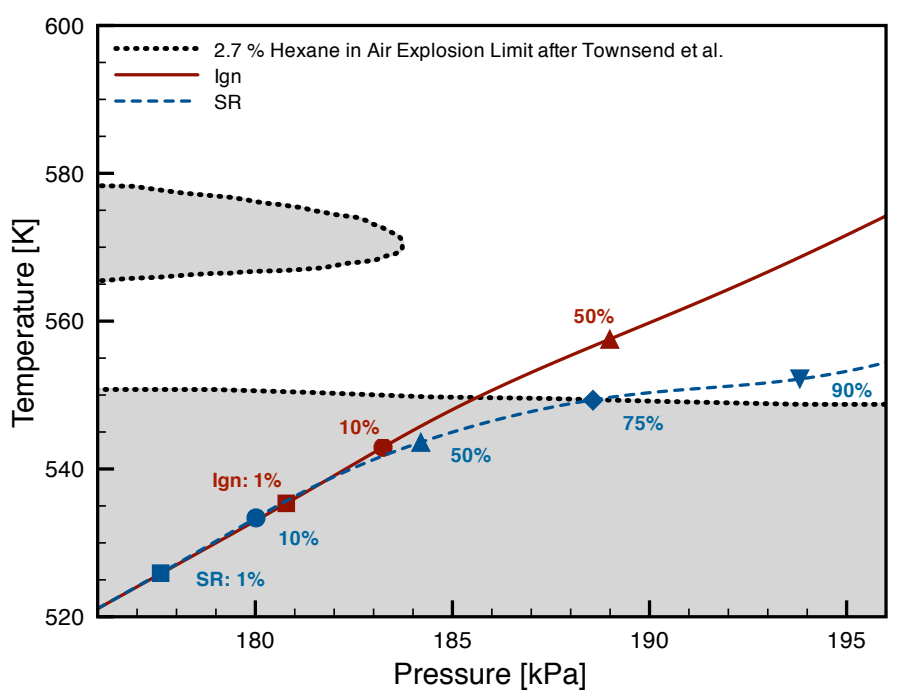

(b)

Figure 14: Thermodynamic state trajectories along with the explosion limits [28] for a $n$ hexane-air mixture with different heating rates. Conditions: $\Phi=1.2 ; \alpha=5$ and $10 \mathrm{~K} / \mathrm{min}$; (a): temporal evolution (500 s elapsed time between points). (b): $n$-hexane percentage consumed in the boxed region of (a). 


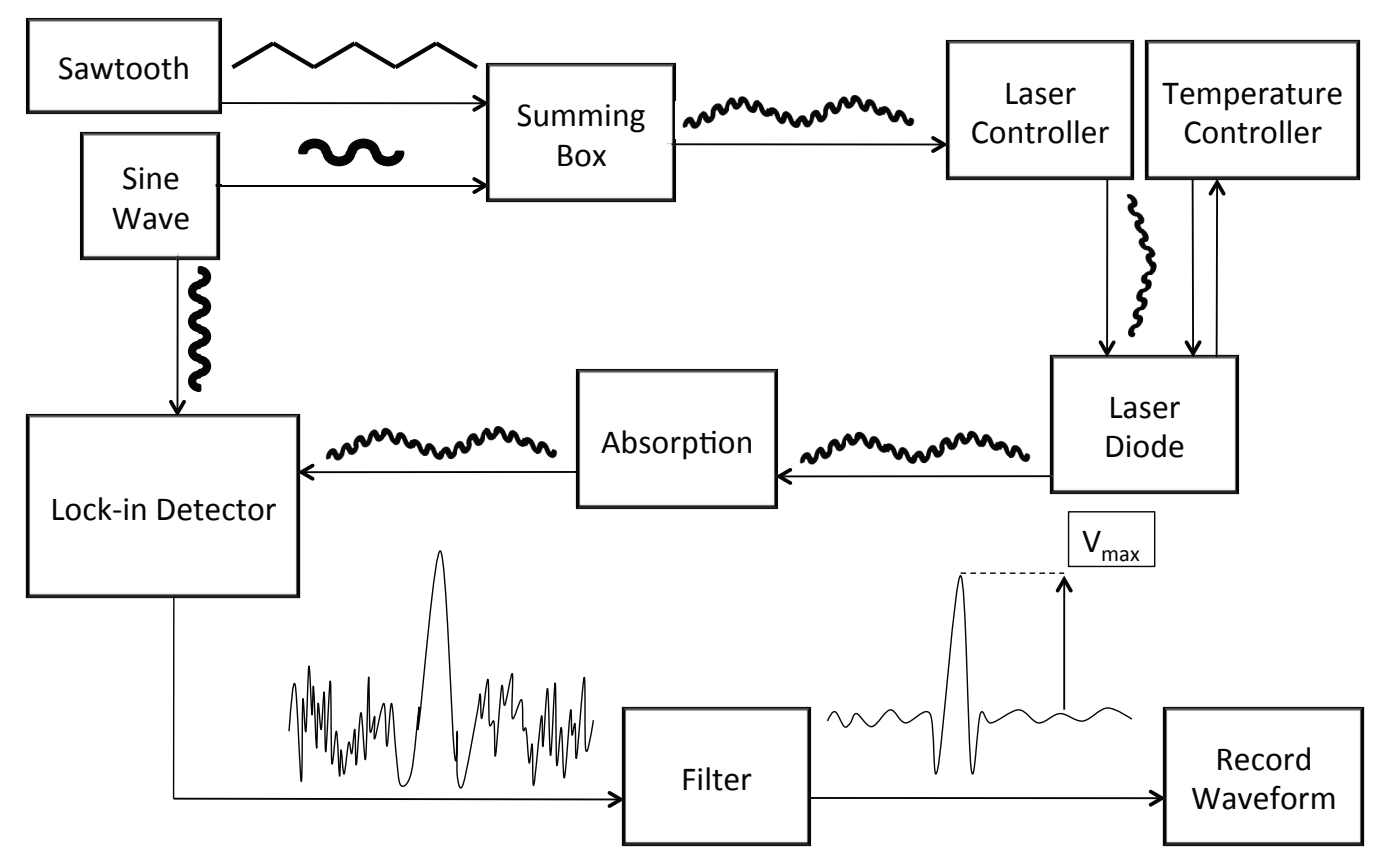

Figure 15: Schematic of the experimental setup for molecular oxygen measurements 


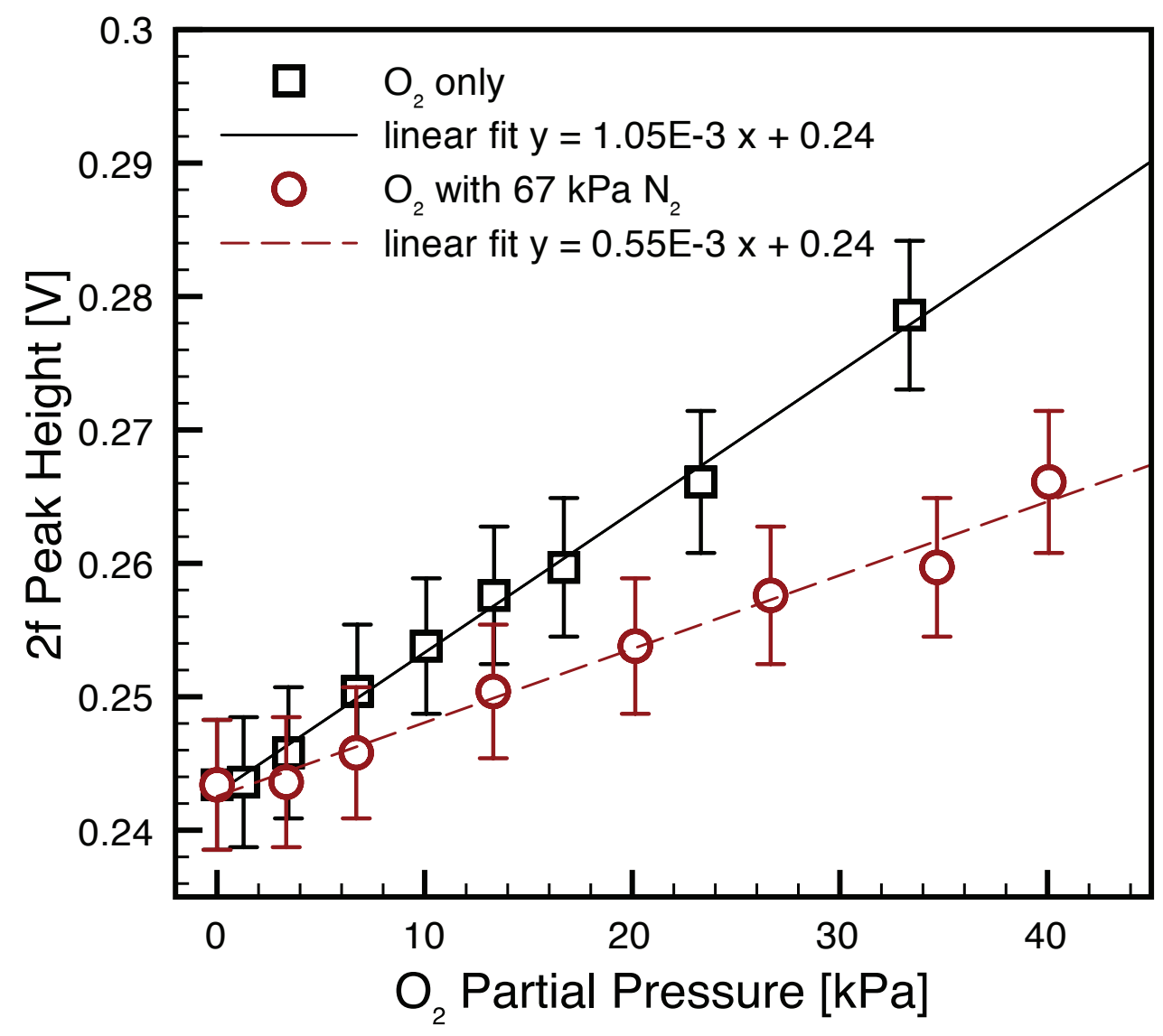

Figure 16: Calibration curve, second harmonic peak height as a function of molecular oxygen partial pressure with $\pm \sigma$ uncertainty bars $\left(\mathrm{O}_{2}\right.$ only and $\mathrm{O}_{2}$ with $67 \mathrm{kPa} \mathrm{N} \mathrm{N}_{2}$ dilution) 


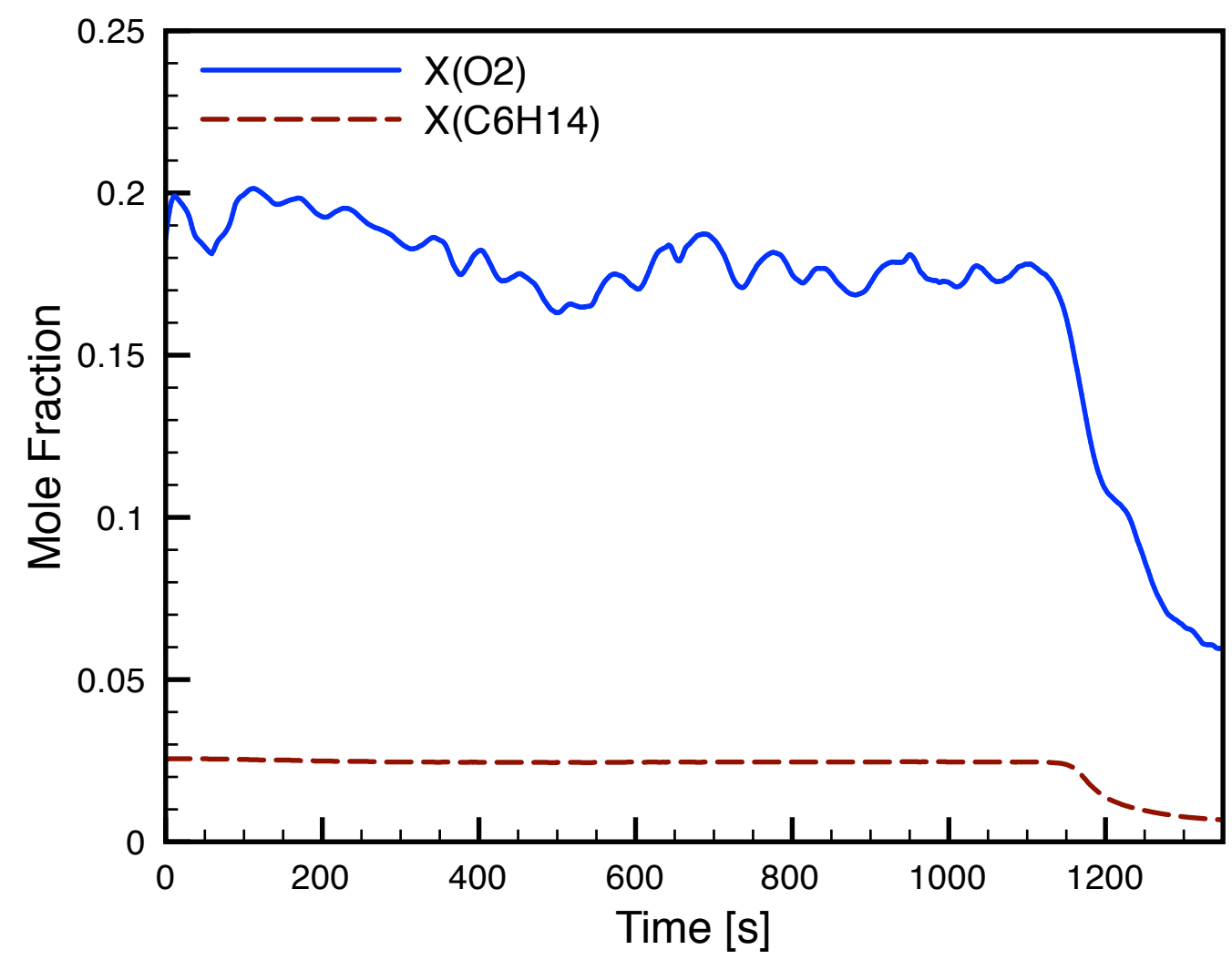

Figure 17: Measurement of the molecular oxygen and fuel concentration during a slow reaction for a $n$-hexane/air mixture. Conditions: $P_{0}=26.67 \mathrm{kPa}, \Phi=1.2, \alpha=11.2$ $\mathrm{K} / \mathrm{min}$ 